\title{
EL INTERÉS GENERAL DE LOS CONSUMIDORES Y SU TUTELA EN LAS DECISIONES DE LOS TRIBUNALES SUPERIORES DE JUSTICIA
}

\author{
THE GENERAL INTEREST OF CONSUMERS AND THEIR \\ PROTECTION IN THE DECISIONS OF THE SUPERIOR \\ COURTS OF JUSTICE
}

\author{
IÑIGO DE LA MAZA GAZMURI* \\ Profesor de Derecho Civil \\ Universidad Diego Portales \\ Santiago - Chile \\ HUGO OJEDA MONTOYA** \\ Magíster en Derecho Civil \\ Universidad Diego Portales \\ Santiago - Chile
}

\section{RESUMEN}

Este trabajo intenta responder dos preguntas relativas al "interés general de los consumidores" tal y como utiliza esta expresión la Ley 19.496. La primera de ellas es qué han entendido los tribunales superiores de justicia de entender por intereses generales de los consumidores. La segunda pregunta se refiere a las facultades que, según dichos tribunales, le concede la ley al Servicio Nacional del Consumidor (en adelante, "SERNAC") cuando dichos intereses se encuentran comprometidos.

\footnotetext{
* Abogado; Doctor en Derecho; Profesor Investigador Facultad de Derecho de la Universidad Diego Portales; Profesor de Derecho Civil; Dirección postal: República 105, Santiago de Chile. Correo electrónico: inigo.delamaza@udp.cl.

** Abogado; Magíster en Derecho Civil Patrimonial; Universidad Diego Portales; Dirección postal: República 105, Santiago de Chile. Correo electrónico: hugo.ojeda@mail.udp.cl. Artículo recibido el 22 de septiembre de 2017 y aceptado para su publicación el 28 de noviembre de 2017.
} 
Palabras clave: Ley 19.496, SERNAC, acciones, interés general de los consumidores.

\section{ABSTRACT}

This paper intends to answer two questions about the "general interest of consumer" as used by article $58 \mathrm{~g}$ ) statute 19.496. First: what is the meaning for courts of this expression. The second question relates to the opinion of courts about the powers conferred to the National Consumers Service (SERNAC) when this kind of interest is involved.

Keywords: Statute $\mathrm{n}^{\circ} 19.496$, SERNAC, actions, general interest of consumers.

\section{INTRODUCCIÓN}

En una presentación en la Facultad de Derecho de la Universidad Alberto Hurtado, el día 5 de septiembre de 2017, Ernesto Muñoz, director de SERNAC, indicó que, desde el año 2014 y hasta julio de 2017, el SERNAC había interpuesto 3.973 acciones por interés general. ${ }^{1}$

Una reciente sentencia de la Corte Suprema, de fecha 23 de enero de 2017, ha señalado que en la Ley 19.496 únicamente existen tres acciones, las de interés individual, colectivo y difuso, ${ }^{2}$ por lo mismo, según esta sentencia, la acción que el SERNAC ha interpuesto 3.973 veces no existe.

Hasta donde llegan nuestras noticias, con posterioridad a esta sentencia, la Corte no ha fallado otros casos semejantes. El panorama, entonces, es suficientemente inquietante, particularmente porque, como revisaremos más adelante, lo resuelto por la Corte Suprema se opone frontalmente a una jurisprudencia abrumadoramente mayoritaria de las Cortes de Apelaciones, por lo menos desde el año 2008 a la fecha. ${ }^{3}$

1 En Congreso Internacional de Derecho de Consumo, "El consumidor y su protección en la venta de bienes de consumo", Universidad Alberto Hurtado, Santiago, 5 de septiembre de 2017.

2 Corte Suprema, 23 de enero de 2017, Rol No 68769-2016, Id. LP CL/JUR/230/2017. Esta misma idea -que no hay una cuarta atención- ya había sido expresada en un voto concurrente del ministro Rubén Ballesteros en Corte Suprema, 25 de agosto de 2011, Rol 4941-2011, Id. LP CL/JUR/6841/2011.

3 De hecho, una sentencia de la Corte de Apelaciones de Concepción, 27 de marzo de 2017, Rol N ${ }^{\circ}$ 64-2017, Id. Vlex No 672259117, reconoce nuevamente la facultad del SERNAC de ejercer acciones distintas a las de interés individual, colectivo y difuso en tutela con el objetivo de tutelar el interés general de los consumidores. 
Aunque la doctrina nacional ha considerado el tema del interés general muy escasamente, lo ha hecho de manera intuitivamente correcta. ${ }^{4}$ Nos parece, sin embargo, que, atendido el enorme número de sentencias en que se trata el tema, una carencia especialmente conspicua en el tratamiento que ha prodigado la doctrina a la cuestión, corresponde a un examen sistemático de la opinión de los tribunales. ${ }^{5}$ La única excepción que hemos sabido encontrar es un valioso trabajo del profesor Jaime Carrasco que considera sentencias entre el año 2009 y $2013 .{ }^{6}$

El avance que proponemos se endereza a través del examen de un abultado número de sentencias de tribunales superiores chilenos dictadas entre el 1 de abril de 2008 y el 27 de marzo de 2017.

El objetivo de este trabajo consiste, entonces, en mostrar el tratamiento que ha recibido el interés general de los consumidores por parte de los tribunales superiores de justicia.

Para desarrollarlo procedemos de la siguiente manera. En primer lugar, mostramos con algún detalle la sentencia de la Corte Suprema a que nos hemos referido ya. En segundo lugar, prestamos atención a las sentencias de las Cortes de Apelaciones con la finalidad de responder a dos preguntas que nos suscita la sentencia de la Corte Suprema. La primera de ellas se refiere a qué hemos de entender por "intereses generales de los consumidores". La segunda pregunta consiste en determinar qué facultades se reconocen al SERNAC cuando dicho interés se encuentra comprometido. Como es habitual, el trabajo termina con un cuerpo de conclusiones.

Las hipótesis que quisiéramos acreditar son dos: la primera de ellas es que no obstante la grandilocuencia de la definición de interés general, la

4 Ver, por ejemplo, IsLer Soto, Erika “Comentario artículo 58” en: De la Maza Gazmuri, Iñigo; Pizarro Wilson, Carlos (directores), La protección de los consumidores, Thomson Reuters, Santiago, 2013, pp. 1148-1150; respecto a la interpretación del artículo $58 \mathrm{~g}$ ) con cierta atención a la opinión de los tribunales y, sobre lo mismo FernÁndez Fredes, Francisco, "Nueva ley del consumidor: innovaciones y limitaciones", Revista Perspectivas, 1998, vol. 1 N $^{\text {o }}$ 2, p. 122. Por su parte, en Poblete Iturrate, Orlando, "Las acciones por intereses colectivos y difusos. Algunas consideraciones básicas", Revista de Derecho Universidad Finis Terrae, 2003, año VII, No 7, p. 283, y Momberg Uribe, Rodrigo, "La autonomía de la acción en interés general de los consumidores del artículo 58 letra g) de la Ley No 19.496 sobre protección de los derechos de los consumidores (LPC) (Corte Suprema)", Revista de Derecho (Valdivia), 2011, vol. XXIV N 2, pp. 235-244, comentando una sentencia de la Corte Suprema.

5 El texto de Carrasco Poblete, Jaime, "La legitimación activa y extraordinaria del SERNAC para velar por los intereses generales de los consumidores", en: Barrientos C., Francisca (coord.), Condiciones generales de la contratación y cláusulas abusivas, Ediciones de la Universidad Diego Portales, Santiago, 2014, pp. 331-348, presta atención a algunas sentencias.

6 Las sentencias que se utilizan en este trabajo fueron buscadas en las principales bases de datos al 30 de agosto de 2017: Vlex, Legal Publishing ("LP") y Microjuris ("MJ"), utilizando como criterios de búsqueda: artículo 58 letra g) de la Ley 19.496, e "interés general". 
aplicación del concepto por parte de los tribunales enseña que este se ocupa prácticamente en cualquier situación. La segunda hipótesis de este trabajo consiste en que las Cortes de Apelaciones, de manera abrumadoramente mayoritaria, se han pronunciado de forma contradictoria a la Corte Suprema, asumiendo que existe una acción destinada a tutelar el interés general de los consumidores, cuyo titular es el SERNAC.

\section{EL CASO Y LAS PREGUNTAS}

El día 4 de octubre de 2013 T4F Chile S.A. (T4F) realizó un concierto presentando a la banda inglesa Black Sabbath. Según indicó la productora, por problemas técnicos procedió a modificar la distribución de las localidades. Con anterioridad a esta modificación, les informó del cambio a quienes habían adquirido localidades. Se le solicitó la devolución de 1.713 entradas, solicitud a la que T4F accedió.

En lo que aquí interesa, el SERNAC interpuso una denuncia fundada en el interés general de los consumidores contra T4F. Las infracciones que reprochó SERNAC al proveedor no son relevantes aquí. Lo que, en cambio, resulta de especial interés es el hecho de que no se trató ni de una acción de interés individual ni de una de interés colectivo o difuso, en el sentido que da a estas expresiones el artículo 50 de la Ley 19.496 sobre protección de los derechos de los consumidores (Ley 19.496). SERNAC justificó su comparecencia ante el Juzgado de Policía Local en virtud de lo dispuesto en el artículo 58 letra g) de la Ley 19.496. Entendió, entonces, de una parte, que en este caso se encontraban comprometidos los intereses generales de los consumidores. Y, de otra, que, cuando esto sucede, se encuentra legitimado para comparecer en juicio.

En el juicio se discutieron varios puntos. Sin embargo, el que aquí interesa se refiere a una de las defensas de T4F, según la cual el Juzgado de Policía Local sería incompetente pues se habría pronunciado sobre una acción inexistente.

El Juzgado de Policía Local no acogió la incompetencia. Por su parte, en una sentencia de 12 de septiembre de 2016, la Primera Sala de la Corte de Apelaciones de Punta Arenas entendió que en este caso SERNAC no estaba utilizando ni una acción de interés individual ni una de interés colectivo o difuso. La acción se ejercía en el interés general de todos los consumidores involucrados. Señaló:

"Así y tal como lo sostenido (sic) esta Corte en la causa rol no 3-2010, la denuncia infraccional deducida aparece como la más idónea para conocer de los hechos denunciados por tratarse de hechos que afectan el interés general de los consumidores, interés que protege a la sociedad toda, por 
lo que resulta más efectivo aplicar el procedimiento establecido en el artículo 50 de la letra a) de la Ley 19.436 (sic) para resolver este caso donde el proveedor no cumplió con la prestación del servicio acorde a lo que establece la ley de protección al consumidor (...)".

Más adelante, la Corte dedica algunas palabras a precisar por qué en este caso se encontraba comprometido el interés general de los consumidores, señalando que se trataba de un evento muy importante para los adeptos a la banda y que habían debido viajar desde Punta Arenas a Santiago: “(...) de allí entonces el interés general de que en eventos de estas características, se respeten los derechos de los consumidores (...)".

En una sentencia de fecha 23 de enero de $2017^{7}$ la Corte Suprema revocó la sentencia recién referida. En el considerando séptimo se encuentra la explicación, en los siguientes términos:

"(...) las acciones judiciales destinadas a resguardar los derechos de los consumidores sólo pueden ejercerse a título individual o en beneficio del interés colectivo o difuso de aquellos.

En consecuencia, no existe en la legislación una cuarta categoría de acciones, como las de interés general que propone el Servicio Nacional del Consumidor, pues si bien el artículo 58 letra g) inciso $2^{\circ}$ de la Ley $\mathrm{N}^{\circ}$ 19.496 dispone que la facultad de dicho Servicio de velar por el cumplimiento de normas establecidas en leyes especiales que digan relación con el consumidor, incluye la atribución de denunciar los posibles incumplimientos ante los organismos o instancias jurisdiccionales respectivos y de hacerse parte en las causas en que estén afectados los intereses generales de los consumidores, la misma norma indica expresamente que ello debe hacerse 'según los procedimientos que fijan las normas generales o los que se señalen en esas leyes especiales'.

Por lo demás, la conclusión anterior guarda relación y total armonía con el hecho de que la ley en examen sólo contempla dos tipos de procedimientos judiciales, el destinado a la protección del interés individual de los consumidores y el regulado en forma especial para la protección del interés colectivo o difuso de los consumidores".

Inmediatamente después, en el considerando octavo, la Corte concluyó que la acción promovida por el SERNAC corresponde a una de interés 
colectivo, pues se trata del interés de consumidores ligados por un contrato con el proveedor, por lo mismo, concluye, el Juzgado de Policía Local resultaba absolutamente incompetente.

La sentencia a que nos hemos referido-y, en general, el caso que resuelvenos descubre la utilidad de un par de preguntas. La primera de ellas consiste en el significado que ha de atribuirse a la expresión "intereses generales de los consumidores".

Sin prejuzgar la forma en que el SERNAC debe concurrir a la tutela de los intereses generales de los consumidores, lo cierto es que la letra g) del artículo 58 lo relaciona con sus funciones y parece establecerlo como requisito para el ejercicio de alguna de estas funciones.

Si se acepta lo anterior-dejando, aún, pendiente cuáles sean exactamente esas funciones- hemos de convenir acerca de la importancia de precisar la noción. La sentencia que hemos utilizado ilustra bien la cuestión. La pregunta que podemos formularnos es la siguiente ¿De qué manera el cambio en las ubicaciones en un concierto de Black Sabbath puede comprometer el interés general de los consumidores? Como adelantamos, la Corte de Apelaciones de Punta Arenas tiene una respuesta para esto. Como se recordará, el tribunal señala que viajaron desde Punta Arenas a Santiago y concluye que "(...) de allí entonces el interés general de que, en eventos de estas características, se respeten los derechos de los consumidores (...)."

Sin embargo, esta respuesta no nos persuade. El razonamiento de la Corte de Apelaciones parece estructurarse en torno a una cierta idea no explicitada de prevención general. Lo que parece sugerir la Corte es que el interés general se justificaría en que en eventos de esa naturaleza se respeten los derechos de los consumidores.

El problema de un argumento como éste es que si funciona, funciona demasiado bien pues lo cierto es que en cualquier caso imaginable de infracción a los derechos de los consumidores existe interés en que se respeten sus derechos.

La segunda pregunta que llama nuestra atención es aquello que habíamos dejado pendiente en la primera, es decir, asumiendo que, efectivamente, haya un interés general de los consumidores comprometido ¿Qué es, exactamente, lo que eso le permite al SERNAC?

Y lo que aprendemos del fallo de la Corte Suprema es más bien que es lo que no le permite. Como ya lo hemos visto, lo que no le permite es interponer una denuncia ante un Juzgado de Policía Local. Y no se lo permite porque no dispondría de una acción, pues las acciones que establece la ley son únicamente las de interés individual, colectivo y difuso. 
Sin embargo, lo cierto es que esta es una idea que debemos reconsiderar pues resulta ser el caso que, como se verá, esa acción ha sido reconocida en múltiples sentencias de tribunales superiores. Podemos ilustrarlo preliminarmente a través de un par de ejemplos, El primero de ellos corresponde a una sentencia de 2 de junio de 2009 de la Corte de Apelaciones de Santiago. ${ }^{8}$ En ella, la Corte estimó que, en virtud de lo dispuesto en el artículo 58 de la Ley 19.496, el SERNAC disponía de facultades para efectuar una denuncia infraccional en contra de Farmacias Salcobrand S.A. por no mantener listados de precios a disposición del público. El segundo ejemplo corresponde a una sentencia de la misma Corte, pero esta vez de 30 de enero de 2015, ${ }^{9}$ que resuelve un caso de intereses que exceden el marco legal autorizado, dispone, casi exactamente, lo contrario a lo que establecía la Corte Suprema en la sentencia examinada más arriba, en los siguientes términos:

"SEPTIMO: Que, en lo concerniente a esta denuncia, el núcleo de la discusión, entiende esta Corte, radica en determinar si, de conformidad a lo previsto en el artículo 58 letra g) de la ley del ramo, el citado servicio se encontraba en el presente caso legitimado para actuar invocando un interés general de los consumidores, frente a la actuación de la denunciada, que sólo habría afectado al denunciante aludido precedentemente, estimando que no habría una afectación a intereses generales de los consumidores. OCTAVO: Que, sobre ello cabe precisar que conforme lo dispone el precepto citado, ésta constituye una acción de aquellas destinadas a proteger intereses supraindividuales, pudiendo sostenerse que existe una cuarta categoría de acciones, más allá de las señaladas en el artículo 50 de la misma ley que contempla las acciones de interés individual, colectivo o difuso.

En cuanto al interés general de los consumidores, cabe señalar que existe autonomía de dicha acción respecto de las tres anteriormente mencionadas, y por tanto se encuentran incluidas en el régimen general de competencia de los Juzgados de Policía Local, entendiendo que la competencia que la Ley de Protección a los Derechos del Consumidor entrega a los tribunales ordinarios, debe ser interpretada restrictivamente frente a la regla general que es la competencia de los citados Juzgados de Policía Local.

NOVENO: Que, cabe dejar sentado que el artículo 58 de la Ley N 19.496 emplea la expresión 'intereses generales de los consumidores' en una

\footnotetext{
8 Corte de Apelaciones de San Miguel, 2 de junio de 2009, Rol N³19-2009, Id. LP CL/JUR/8305/2009.
}

9 Corte de Apelaciones de Santiago, 30 de enero de 2015, Rol 1523-2014, Id. MJ MJJ40425. 
acepción más amplia que la del 'interés colectivo o difusơ que menciona el artículo 50 de la misma ley, toda vez que por tal interés general, se entiende el interés de la sociedad política, utilizada generalmente como sinónimo de interés público o bien común, establecido además como fin del Estado y de sus órganos en el artículo $1^{\circ}$ de la Constitución Política de la República, y que aquí se particulariza en un aspecto del mismo, a saber, los consumidores en sentido genérico, y no como un grupo, específico e individualizado de los mismos, de donde cabe descartar la circunstancia de supuesta falta de legitimación para el ejercicio de la presente acción derivada de la circunstancia de haberse constatado la afectación de una sola persona, pues ello en nada afecta la consideración efectuada en cuanto a lo que ha de entenderse por interés general, dado que el mismo engloba a la sociedad toda, considerada como potencial consumidora desde la perspectiva de la ley del ramo, y por ende, como posible de verse afectada en sus intereses, de donde se colige que el citado servicio debe intervenir en tales casos por mandato del señalado artículo 58 letra g).

DÉCIMO: Que, a lo anterior cabe agregar la naturaleza misma del interés general de los consumidores, lo que permite diferenciarlo del interés colectivo o difuso, y aunque no está definido en la ley, permite conceptualizarlo como "aquel que protege a la sociedad toda". A ello se suma que la determinación del interés general de los consumidores se basa en un criterio cualitativo, cual es la protección a los consumidores en cuanto grupo abstracto de sujetos para el caso de violación a sus derechos esenciales, lo que claramente difiere del interés colectivo en cuanto éste dice relación con la defensa de derechos comunes a un conjunto determinado o determinable de consumidores, ligados con un proveedor por un vínculo contractual, conforme lo dispone el artículo 50 ya citado, y el interés difuso es aquel que se relaciona con la defensa de un conjunto indeterminado de consumidores afectados en sus derechos. De esta forma el interés colectivo o difuso implica siempre en su sustrato la existencia de intereses individuales, sólo que acumulados para efectos de coherencia y economía procesal, de manera de evitar fallos divergentes y lograr una decisión uniforme en el caso particular.

Otro punto a considerar, es el objeto que persigue cada una de las acciones diferenciadas, así la acción en el interés general, cuyo único legitimado es el SERNAC, persigue la sanción infraccional del proveedor que con su conducta ha afectado el mencionado interés general de los consumidores, al haber infringido normas de la ley del ramo, procesalmente, se trata entonces, de una denuncia que busca la 
sanción infraccional del proveedor por medio de la imposición de una multa, y no una demanda que pretenda efectos civiles, como si sería procedente tratándose del interés colectivo o difuso.

UNDECIMO: Que por lo referido, no parece lógico ni razonable forzar al Servicio aludido a ejercer en exclusiva la acción infraccional en sede civil, procedimiento mucho más complejo y de lato conocimiento".

Se trata de una cita particularmente extensa; sin embargo, muestra con particular elocuencia los dos aspectos de interés a este trabajo como para tomársela en serio. En primer lugar, define qué debe entenderse por interés general: el de la sociedad toda, como una cuestión distinta a los intereses individuales, ya sea que se presenten de esa manera o acumulados en acciones de interés colectivo o difuso. En segundo lugar, señala que existe una cuarta categoría de acciones, las de interés general y que el único titular es el SERNAC.

\section{INTERESES GENERALES DE LOS CONSUMIDORES: NOCIÓN Y APLICACIÓN}

Según hemos adelantado, nuestro primer interés consiste en intentar precisar el significado que asignan los tribunales a la expresión "interés general de los consumidores". La sentencia de la Corte de Apelaciones de Santiago de 30 de enero de 2015 ya citada, nos enseña un camino para responder a esa pregunta. Este primer camino consiste en intentar detectar qué han entendido, conceptualmente, los tribunales chilenos por intereses generales de los consumidores.

Sin embargo, al comparar las sentencias que hemos considerado hasta ahora, aprendemos que una es sobre un concierto de Black Sabbath, otra sobre listas de precios en farmacias, ${ }^{10}$ la tercera sobre cobros excesivos de intereses, ${ }^{11}$ pero, en fin, según lo veremos al examinar el contexto, hay mucho más.

Esta diversidad de contextos nos sugiere un segundo camino para

\footnotetext{
${ }^{10}$ Corte de Apelaciones de San Miguel, 2 de junio de 2009, Rol N 319-2009, Id. LP CL/JUR/8305/2009. En el mismo sentido, Corte de Apelaciones de San Miguel, 29 de marzo de 2010, Rol N 124-2010, Id. Vlex 226548731; Corte de Apelaciones de Santiago, 28 de octubre de 2013, Rol No 1141-2013, Id. Vlex 637429565; Corte de Apelaciones de Coyhaique, 5 de diciembre de 2013, Rol No 37-2013, Id. Vlex 576767510 .

${ }^{11}$ Corte de Apelaciones de Concepción, 1 de abril de 2008, Rol No 2054-2005, Id. LP CL/ JUR/5632/2008. En el mismo sentido: Corte de Apelaciones de Santiago, 29 de agosto de 2014, Rol $\mathrm{N}^{\circ}$ 2147-2013, Id. Vlex 577716522; Corte de Apelaciones de Santiago, 30 de enero de 2015, Rol N ${ }^{\circ}$ 1523-2014, Id. MJ MJJ40423; Corte de Apelaciones de Santiago, 11 de diciembre de 2015, Rol N ${ }^{\circ}$ 1077-2015, Id. LP CL/JUR/7746/2015.
} 
considerar el alcance de la expresión "intereses generales" y, consiste, precisamente en prestar atención al tipo de casos en que los tribunales han reconocido la presencia de un interés general de los consumidores afectados.

\subsection{La noción de "interés general"}

Nuestra pregunta puede formularse de la siguiente manera: ¿Qué han entendido los tribunales superiores de justicia por "intereses generales de los consumidores"?

Una mirada a las sentencias de tribunales superiores nos enseña que parece tratarse de un tipo de interés más amplio que el de quienes eventualmente comparecen al juicio o incluso al de quienes pueden alcanzar los efectos de la sentencia.

No es infrecuente que los tribunales entiendan que los intereses generales de los consumidores corresponden a asuntos de interés de la sociedad en su conjunto. Así, por ejemplo, una sentencia de la Corte de Apelaciones de Concepción el 1 de abril de $2008,{ }^{12}$ en la que, conociendo de un caso por cobro excesivo de intereses por uso de tarjeta bancaria, entendió que interés general corresponde:

“(...) al interés público, al interés de la sociedad toda, es decir, se promueve en defensa de un conjunto indeterminado de consumidores afectados en sus derechos, formando parte de lo que en doctrina se conoce como acciones de clases (...)".

Así también lo entendió la Corte de Apelaciones de Antofagasta en un fallo de 6 de enero de $2012,{ }^{13}$ señalando además que en este concepto:

"(...) deben considerarse tanto aquellas referidas a hechos que perjudican efectivamente a un grupo significativo de consumidores o usuarios, en la prestación de un servicio, cuanto aquellas que conciernen en concreto y en particular a solo dos personas, como ocurre en el caso de autos, pero que son susceptibles de afectar a la generalidad de los consumidores o usuarios, principalmente dada la frecuencia, gravedad y grado de peligrosidad con que ciertos hechos o actos se presentan o pueden presentarse en una determinada relación de consumo, de manera que resulta del todo

${ }^{12}$ Corte de Apelaciones de Concepción, 1 de abril de 2008, Rol N ${ }^{\circ}$ 2054-2005, Id. LP CL/ JUR/5632/2008. En el mismo sentido: Corte de Apelaciones de Temuco, 30 de julio de 2012, Rol N ${ }^{\circ}$ 92-2012, Id. LP CL/JUR/1531/2012; Corte de Apelaciones de Temuco, 2 de octubre de 2012, Rol N ${ }^{\circ}$ 118-2012, Id. Vlex 403150278.

${ }^{13}$ Corte de Apelaciones de Antofagasta, 6 de enero de 2012, Rol № 195-2011, Id. Vlex 563556822. 
irrelevante para la calificación el que una determinada acción aparezca interpuesta a nombre de sólo dos consumidores afectados".

En el mismo sentido, una sentencia de la Corte de Apelaciones de Temuco del 30 de julio de $2012^{14}$ señala que el interés es:

"(...) un concepto más amplio que el de interés colectivo o difuso que menciona el art. 50 de la ley 19.496, toda vez que por "interés general" se entiende el interés de la sociedad política, utilizándose generalmente como sinónimo de interés público o bien común, establecido además como fin del Estado, y de sus órganos en el art.1 de la Constitución Política del Estado, y que aquí se particulariza en un aspecto del mismo como es "los consumidores" en sentido genérico y no como un grupo específico de los mismos".

A mayor abundamiento, la Corte de Apelaciones de Santiago resolvió el 4 de septiembre de $2014^{15}$ que:

" $5^{\circ}$ ) El interés general engloba a la sociedad toda, considerada como consumidora desde la perspectiva de la Ley $\mathrm{N}^{\circ} 19496$ y lo que debe hacerse es su resguardo exista o no una acción particular en la que el SERNAC deba intervenir por mandato del señalado artículo $59 \mathrm{~g}$ ) (sic). De tal forma, cuando el SERNAC actúa en el interés general -cuyo único legitimado activo es él- el objeto es la sanción del proveedor, que con su conducta ha infringido normas de la Ley $\mathrm{N}^{\circ} 19.496$ que afectan el interés general de los consumidores.

$6^{\circ}$ ) Que, la defensa del interés general no conlleva avalar derechos subjetivos, como sí ocurre con las acciones de interés colectivo o difuso, que pueden significar el pago de indemnizaciones a los consumidores. El interés general únicamente avala intereses públicos, que en el caso del artículo 58 letra g) se expresa en el ejercicio de la actividad de policía administrativa que le cabe al SERNAC, entendida ésta como el medio por el cual se manifiesta el poder público de la administración de una forma coercitiva, a través del Estado; limitando los derechos y libertades en beneficio de los consumidores (...)".

En términos muy semejantes, la sentencia de la Corte de Apelaciones de Santiago del 27 de julio de $2016,{ }^{16}$ se refiere al "interés de toda la sociedad en

\footnotetext{
${ }^{14}$ Corte de Apelaciones de Temuco, 30 de julio de 2012, Rol N 92-2012, Id. Vlex 395476190.

${ }^{15}$ Corte de Apelaciones de Santiago, 4 de septiembre de 2014, Rol № 538-2014, Id. Vlex 581381766.

${ }^{16}$ Corte de Apelaciones de Santiago, 27 de julio de 2016, Rol N 476-2016, Id. Vlex 646927377.
} 
su conjunto" y añade que: "(...) intereses generales de los consumidores puede ser entendido como sinónimo de interés público o bien común". ${ }^{17}$

Finalmente, en un fallo reciente del 27 de marzo de $2017,{ }^{18}$ la Corte de Apelaciones de Concepción ratificó las nociones de interés general señaladas anteriormente, y agregó que

"9.- Que, por "causas en que estén afectados los intereses generales de los consumidores" deben entenderse aquellas referidas a hechos que, o bien afecten efectivamente a un grupo significativo de consumidores o usuarios, o bien que, aun cuando afecten en concreto y en particular a una persona, sean susceptibles de afectar a la generalidad de los consumidores o usuarios.

Entonces los intereses generales de los consumidores pueden afectar en un juicio en concreto a una sola persona consumidora o a un grupo de personas o consumidores.

Por ello, el SERNAC puede iniciar válidamente acciones tanto en causas individuales o colectivas pues el interés general protege a toda la sociedad".

Por lo anterior, y de acuerdo a las decisiones citadas, se puede colegir que la jurisprudencia ha entendido el concepto "interés general de los consumidores" como aquel interés público que, de alguna manera, compromete a la sociedad en su conjunto ${ }^{19} \mathrm{o}$ al bienestar general. ${ }^{20}$ Algo así como "un interés de la comunidad toda y en su conjunto". ${ }^{21}$

${ }^{17}$ Otras sentencias se sirven del significado que adjudica el Diccionario de la RAE a general, como "común y esencial a todos los individuos que constituyen un todo, o a muchos objetos aunque sean de materia diferente". Ver, por ejemplo, sentencia de la Corte de Apelaciones de San Miguel, 21 de marzo de 2014, Rol N 122-2014, Id. LP CL/JUR/491/2014; Corte de Apelaciones de Santiago, 29 de octubre de 2014, Rol N 967-2014, Id. Vlex 582329050.

${ }^{18}$ Corte de Apelaciones de Concepción, 27 de marzo 2017, Rol № 64-2017, Id. Vlex 672259117.

${ }^{19}$ Con alguna frecuencia los tribunales emplean la expresión "sociedad política". V. por ejemplo, Corte de Apelaciones de Santiago, 24 de diciembre de 2015, Rol N 1361-2015, Id. LP CL/JUR/8065/2015; Corte de Apelaciones de Santiago, 14 de agosto de 2013, Rol N 291-2013, Id. LP CL/JUR/1830/2013; Corte de Apelaciones de Santiago, 3 de abril de 2014, Rol No 1867-2013, Id. LP CL/JUR/858/2014; Corte de Apelaciones de Santiago, 3 de noviembre de 2016, Rol N 1294-2016, Id. LP 653216493; Corte de Apelaciones de Santiago, 14 de diciembre de 2016, Rol N² 287-2016, Id. Vlex CL/JUR/8341/2016. En otras ocasiones se emplea la expresión "sociedad toda", ver sentencia de la Corte de Apelaciones de Santiago, 25 de septiembre de 2014, Rol N 646-2014, Id. Vlex 581341454; Corte de Apelaciones de Santiago, 13 de mayo de 2015, Rol N 92-2015, Id. Vlex 569854154.

${ }^{20}$ V. por ejemplo, Corte de Apelaciones de Temuco, 2 de octubre de 2012, Rol № 118-2012, Id. Vlex 403150278.

${ }^{21}$ Corte de Apelaciones de Punta Arenas. 24 de enero de 2013, 7 de octubre de 2016, Rol N ${ }^{\circ} 245-2012$, Id. Vlex 634692185. 
Ahora bien, resulta interesante advertir que la forma en que se compromete la sociedad es, por decirlo de alguna manera, abstracta ${ }^{22} \mathrm{o}$ mediata, pues resulta perfectamente posible que de manera inmediata esté afectado un solo consumidor, como de hecho ha sucedido ${ }^{23} \mathrm{o}$, incluso, aunque no exista ningún consumidor afectado. Así, por ejemplo, en la sentencia de la Corte de Apelaciones de Santiago de 14 de agosto de $2013^{24}$ se lee lo siguiente:

“(...) el concepto de interés general engloba a la sociedad toda, considerada como consumidora desde la perspectiva de la Ley $\mathrm{N}^{\circ}$ 19.496 y lo que debe hacerse en su resguardo, exista o no una acción en particular en la que el SERNAC deba intervenir por mandato del señalado artículo 58 letra g)".

Y es que, como señala la sentencia de la Corte de Apelaciones de Santiago de 8 de noviembre de $2012,{ }^{25}$ se trata de acciones que trascienden la salvaguarda de los interese de un grupo determinado de consumidores, sino que va más allá de ellos.

Por otra parte, hemos de advertir que los tribunales han fallado que no existe incompatibilidad en que un mismo ilícito afecte un interés individual y aquellos generales de los consumidores. ${ }^{26}$

Pues bien, una mirada a la forma en que las Cortes de Apelaciones han empleado la expresión "interés general" nos muestra que lo equipara al interés de la sociedad en su conjunto o, al menos, a un tipo de interés que excede al de los consumidores identificados o identificables en un caso particular.

Nos parece, sin embargo, que la búsqueda no queda completa si se la limita al concepto que entregan los tribunales, pues al indagar en las sentencias en busca de ese concepto aprendemos, además, los casos en que se ha aplicado $y$, según veremos a continuación, en muchos de ellos resulta francamente

${ }_{22}^{2}$ De hecho, la sentencia de la Corte de Apelaciones de Valdivia, 7 de octubre de 2016, Rol № 2602016, Id. Vlex 655099985 se refiere, explícitamente, a la tutela de los consumidores en cuanto "grupo abstracto". La misma expresión en la sentencia de la Corte de Apelaciones de Valdivia, 27 de septiembre de 2016, Rol 257-2016, Id. Vlex 674594373.

${ }^{23}$ Así, por ejemplo, en las sentencias de la Corte de Apelaciones de Temuco, 2 de marzo de 2012, Rol $\mathrm{N}^{\circ}$ 109-2011, Id. Vlex 573022446; Corte de Apelaciones de Arica, 13 de diciembre de 2012, Rol N ${ }^{\circ}$ 51-2012, Id. Vlex 412708150; Corte de Apelaciones de Santiago, 14 de marzo de 2013, Rol $N^{\circ}$ 6822012, Id. Vlex 632020661; Corte de Apelaciones de Santiago, 15 de marzo de 2013, Rol N 176-2012, Id. Vlex 563495622.

${ }^{24}$ Corte de Apelaciones de Santiago, 14 de agosto de 2013, Rol № 291-2013, Id. LP CL/JUR/1830/2013.

${ }^{25}$ Corte de Apelaciones de Santiago, 8 de noviembre de 2012, Rol № 2234-2011, Id. Vlex 573058030.

${ }^{26}$ Corte de Apelaciones de Concepción, 28 de diciembre de 2012, Rol № 203-2012, Id. Vlex 579585018. 
artificioso -o derechamente inexacto- afirmar que se encuentra involucrado un interés de la comunidad en su conjunto.

\subsection{La aplicación}

Nuestra pregunta ahora es la siguiente: ¿Ante qué tipo de casos han entendido las Cortes de Apelaciones que se encuentra comprometido el interés general de los consumidores?

Para responderla, prestaremos atención a casos en que, entre los años 2008 y 2017, en que las Cortes de Apelaciones han considerado que el interés general de los consumidores se encuentra involucrado.

Así, por ejemplo, en un caso sobre incumplimiento de solicitud de antecedentes sobre crédito otorgado por una tienda de retail, ${ }^{27}$ de incumplimiento de los servicios ofrecidos por agencia de turismo, ${ }^{28}$ de falta de fecha de vigencia de una oferta de paquete turístico ${ }^{29}$ de carrera de perito en criminalística, ${ }^{30}$ de garantía legal de producto electrónico, ${ }^{31}$ de operaciones no reconocidas en tarjeta de crédito o cuenta bancaria, ${ }^{32}$ de publicidad engañosa de crédito ofrecido por

${ }^{27}$ Corte de Apelaciones de Santiago, 23 de junio de 2010, Rol N 904-2010, Id. Vlex 233685551

${ }^{28}$ Corte de Apelaciones de Concepción, 27 de octubre de 2010, Rol № 273-2010, Id. MJ MJJ25391. En el mismo sentido: Corte de Apelaciones de Santiago, 24 de abril de 2015, Rol No 1078-2014, Id. LP CL/JUR/2282/2015; Corte Suprema, 30 de junio de 2015, Rol N 5840-2015, Id. Vlex 576395738.

${ }^{29}$ Corte de Apelaciones de Iquique, 21 de agosto de 2015, Rol N 48-2015, Id. LP CL/JUR/4766/2015.

${ }^{30}$ Corte Suprema, 27 de julio de 2010, Rol No 2917-2010, Id. MJ MJJ24421. En el mismo sentido: Corte Suprema, 25 de agosto de 2011, Rol No 4941-2011, Id. LP CL/JUR/6841/2011; Corte de Apelaciones de Concepción, 8 de abril de 2015, Rol N 41-2014, Id. Vlex 577682150.

${ }^{31}$ Corte de Apelaciones de Concepción, 1 de marzo de 2011, Rol N 449-2010, Id. LP CL/ JUR/1677/2011.

${ }^{32}$ Corte de Apelaciones de Iquique, 4 de mayo de 2011, Rol N 15-2011, Id. Vlex 275584931. En el mismo sentido: Corte de Apelaciones de Antofagasta, 6 de enero de 2012, Rol № 195-2011, Id. Vlex 563556822; Corte de Apelaciones de San Miguel, 21 de marzo de 2012, Rol 106-2012, Id. LP CL/ JUR/681/2012; Corte de Apelaciones de Santiago, 15 de marzo de 2013, Rol N 176-2012, Id. Vlex 563495622; Corte de Apelaciones de Antofagasta, 6 de diciembre de 2013, Rol N 131-2013, Id. MJ MJJ36768; Corte de Apelaciones de Santiago, 3 de abril de 2014, Rol № 1867-2013, Id. LP CL/ JUR/858/2014; Corte de Apelaciones de Santiago, 20 de agosto de 2014, Rol N 513-2014, Id. Vlex 579425090; Corte de Apelaciones de Santiago, 25 de septiembre de 2014, Rol № 646-2014, Id. Vlex 581341454; Corte de Apelaciones de Valdivia, 19 de noviembre de 2014, Rol N 195-2014, Id. Vlex 544709678; Corte de Apelaciones de Santiago, 30 de junio de 2015, Rol N 409-2015, Id. MJ MJJ41951; Corte de Apelaciones de Santiago, 7 de agosto de 2015, Rol No 748-2015, Id. Vlex 579880230; Corte de Apelaciones de Santiago, 13 de julio de 2016, Rol № 545-2016, Id. Vlex 645601129. 
Banco, ${ }^{33}$ de negativa del proveedor de entregar contrato de línea de crédito,${ }^{34} \mathrm{de}$ cobros indebidos por uso en tarjeta de crédito, ${ }^{35}$ de discriminación al otorgar un crédito de consumo bancario, ${ }^{36}$ de sobreprecio o recargo en el precio de entrada de espectáculo, ${ }^{37}$ de cambio de fecha y lugar de concierto de banda musical, ${ }^{38}$ de cancelación de concierto musical, ${ }^{39}$ de repactación unilateral ${ }^{40}$ de precio incorrecto de un pote de margarina, ${ }^{41}$ de privación del derecho libre elección de la elección del medicamento genérico de "Clonazepam", ${ }^{42}$ de falta de información sobre valor final de créditos bancarios y productos relacionados, ${ }^{43}$ de compra de una máquina de $\operatorname{coser},{ }^{44}$ de mal funcionamiento de una escalera mecánica, ${ }^{45}$ de robo de automóvil (o de especies depositadas en él) aparcado en

${ }^{33}$ Corte de Apelaciones de Temuco, 2 de marzo de 2012, Rol № 109-2011, Id. Vlex 573022446. En el mismo sentido: Corte de Apelaciones de Santiago, 30 de octubre de 2014, Rol N 765-2014, Id. LP CL/JUR/8014/2014.

${ }^{34}$ Corte de Apelaciones de Talca, 3 de abril de 2014, Rol No 3035-2013, Id. LP CL/JUR/871/2014.

${ }^{35}$ Corte de Apelaciones de Santiago, 11 de abril de 2013, Rol No 1141-2012, Id. Vlex 579571038. En el mismo sentido, Corte de Apelaciones de Talca, 2 de mayo de 2014, Rol N 2682-2013, Id. LP CL/ JUR/1994/2014.

${ }^{36}$ Corte de Apelaciones de Santiago, 10 de junio de 2013, Rol N 400-2012, Id. Vlex 563462258.

${ }^{37}$ Corte de Apelaciones de Santiago, 30 de noviembre de 2011, Rol No 1264-2011, Id. LP CL/ JUR/8835/2011.

${ }^{38}$ Corte de Apelaciones de Santiago, 12 de junio de 2012, Rol N 1781-2011, Id. LP CL/JUR/1086/2012. En el mismo sentido: Corte Suprema, 23 de enero de 2017, Rol N ${ }^{\circ}$ 68769-2016, Id. LP CL/ JUR/230/2017; Corte Suprema, 23 de enero de 2017, Rol Nº 68771-2016, Id. LP CL/JUR/229/2017.

${ }^{39}$ Corte de Apelaciones de Concepción, 20 de julio de 2015, Rol No 458-2014, Id. Vlex 631916801.

${ }^{40}$ Corte de Apelaciones de Temuco, 30 de julio de 2012, Rol N 92-2012, Id. LP CL/JUR/1531/2012. En el mismo sentido: Corte de Apelaciones de Santiago, 15 de abril de 2014, Rol N 792-2013, Id. LP CL/JUR/1353/2014; Corte de Apelaciones de Santiago, 4 de septiembre de 2014, Rol N 538-2014, Id. Vlex 581381766.

${ }^{41}$ Corte de Apelaciones de Arica, 13 de diciembre de 2012, Rol N 51-2012, Id. Vlex 412708150; Corte de Apelaciones de Santiago, 8 de noviembre de 2012, Rol N 2234-2011, Id. Vlex 573058030.

${ }^{42}$ Corte de Apelaciones de Punta Arenas, 24 de enero de 2013, Rol N 2445-2012, Id. Vlex 6346921185.

${ }^{43}$ Corte de Apelaciones de Santiago, 14 de marzo de 2013, Rol N 399-2012, Id. LP CL/JUR/845/2013.

${ }^{44}$ Corte de Apelaciones de Santiago, 14 de marzo de 2013, Rol N 682-2012, Id. Vlex VLEX632020661 .

${ }^{45}$ Corte de Apelaciones de Rancagua, 31 de mayo de 2013, Rol № 44-2013, Id. Vlex VLEX-586509838. 
el estacionamiento del proveedor, ${ }^{46}$ de publicidad engañosa, ${ }^{47}$ de modificación de itinerario de vuelo, ${ }^{48}$ de error de test de embarazo, ${ }^{49}$ de imposibilidad de elección de matrona que asistirá parto, ${ }^{50}$ de clonación de tarjeta de cuenta corriente, ${ }^{51}$ de incumplimiento de publicidad sobre precio de "hot dog", ${ }^{52}$ de cobros indebidos por servicios de telefonía no prestados, ${ }^{53}$ de negativa del proveedor al derecho de retracto de una suscripción de membresía a "Club New World Beauty", 54 de publicidad engañosa respecto a descuentos en precio de juguetes ${ }^{55}$ de incumplimientos de ventas celebradas por internet, ${ }^{56}$ de cobranza extrajudicial abusiva, ${ }^{57}$ de venta de productos peligrosos para la salud ${ }^{58}$ de venta atada,${ }^{59}$ de rotulado de alimentos para mascotas, ${ }^{60}$ de cobro de precio superior al publicitado

${ }^{46}$ Corte de Apelaciones de Concepción, 3 de junio de 2013, Rol N 78-2013, Id. Vlex 642353149. En el mismo sentido: Corte de Apelaciones de Santiago, 15 de julio de 2013, Rol N 1779-2012, Id. Vlex 581436026; Corte de Apelaciones de Santiago, 9 de octubre de 2013, Rol № 951-2013, Id. Vlex 589950470; Corte de Apelaciones de Puerto Montt, 4 de mayo de 2015, Rol N 16-2015, Id. Vlex 569848690; Corte de Apelaciones de Santiago, 27 de julio de 2016, Rol N 476-2016, Id. Vlex 646927377. En sentido contrario, v. Corte de Apelaciones de Concepción, 1 de diciembre de 2016, Rol 396-2016, Id. Vlex 654595209, que señala que compromete únicamente un interés individual.

${ }^{47}$ Corte de Apelaciones de Santiago, 25 de junio de 2013, Rol N 1389-2012, Id. LP CL/JUR/1394/2013. En el mismo sentido: Corte de Apelaciones de Concepción, 10 de septiembre de 2014, Rol N ${ }^{\circ} 24-2014$, Id. Vlex 577689646; Corte de Apelaciones de Santiago, 2 de diciembre de 2014, Rol N 883-2014, Id. MJ MJJ39680. Corte de Apelaciones de Santiago, 30 de enero de 2015, Rol N 1529-2014, Id. MJ MJJ40425; Corte de Apelaciones de Santiago, 14 de diciembre de 2016, Rol N 1047-2015, Id. LP CL/JUR/9340/2016.

${ }^{48}$ Corte de Apelaciones de Coyhaique, 8 de julio de 2013, Rol N²4-2013, Id. Vlex 637440973.

${ }^{49}$ Corte de Apelaciones de Santiago, 20 de agosto de 2013, Rol N 67-2013, Id. LP CL/JUR/1863/2013.

${ }^{50}$ Corte de Apelaciones de Valdivia, 21 de agosto de 2015, Rol N 135-2015, Id. LP CL/JUR/4772/2015.

${ }^{51}$ Corte de Apelaciones de Santiago, 23 de octubre de 2013, Rol № 619-2013, Id. Vlex 586482642.

52 Corte de Apelaciones de Santiago, 30 de octubre de 2013, Rol N ${ }^{\circ}$ 1253-2013, Id. LP CL/ JUR/2404/2013.

${ }^{53}$ Corte de Apelaciones de Talca, 22 de noviembre de 2013, Rol № 714-2013, Id. Vlex 590006274.

${ }^{54}$ Corte de Apelaciones de Santiago, 26 de noviembre de 2013, Rol N 1573-2013, Id. MJ MJJ36427.

${ }^{55}$ Corte de Apelaciones de Santiago, 30 de abril de 2014, Rol N²087-2013, Id. LP CL/JUR/1866/2014.

${ }_{56}$ Corte de Apelaciones de Concepción, 9 de junio de 2014, Rol N²94-2013, Id. Vlex VLEX563435290. En el mismo sentido, Corte de Apelaciones de Santiago, 15 de junio de 2016, Rol N ${ }^{\circ}$ 405-2016, Id. Vlex 646944973.

${ }^{57}$ Corte de Apelaciones de Santiago, 5 de enero de 2015, Rol № 1403-2014, Id. MJ MJJ40061.

${ }^{58}$ Corte de Apelaciones de Santiago, 6 de enero de 2015, Rol № 1464-2014, Id. Vlex 591278530.

${ }^{59}$ Corte de Apelaciones de Valdivia, 2 de febrero de 2015, Rol No 179-2014, Id. LP CL/JUR/535/2015.

${ }^{60}$ Corte de Apelaciones de San Miguel, 18 de mayo de 2015, Rol No 761-2015, Id. Vlex 571428686; Corte de Apelaciones de Santiago, 31 de agosto de 2015, Rol N 822-2015, Id. LP CL/JUR/4968/2015. 
en vitrina, ${ }^{61}$ acerca del hecho de que no se entregaran audífonos en un bus, ${ }^{62}$ de firma no reconocida en contrato de tarjeta de crédito o seguro, ${ }^{63}$ de negativa de instalación de servicios de telefonía e internet, ${ }^{64}$ de envío de publicidad no deseada vía mensaje de texto, ${ }^{65}$ de publicidad ilegible e incomprensible, ${ }^{66}$ de falta de información sobre "parches de desintoxicación", ${ }^{67}$ etc.

Pues bien, por supuesto los casos que hemos considerado no son todos, ni tenemos pretensiones acerca de su valor muestral respecto del universo de casos, sin embargo, creemos que son suficientes para presentar el punto que nos interesa y es un desajuste suficientemente evidente entre la forma en que las Cortes de Apelaciones definen el interés general y las situaciones en las cuales consideran que éste se encuentra comprometido.

Según nos parece, la conclusión que se puede obtener de estas sentencias es que lo cierto es que no existe nada peculiar en la mayoría de ellos que nos lleve a pensar que está comprometido algo distinto al interés individual, colectivo o difuso en ellos. Por lo mismo, según nos parece, existe una tendencia suficientemente acentuada por parte de las Cortes de Apelaciones de vaciar del significado que ellas mismas le han asignado al interés general de los consumidores cuando lo aplican.

Con todo, encontramos sentencias -aunque de manera extremadamente minoritaria que se toman más en serio la noción de interés general. En este sentido, nos parece especialmente valiosa la sentencia de la Corte de Apelaciones de Santiago del 24 de abril de 2015, que resuelve un caso en el que el incumplimiento de Latam dejó a una pasajera sin asiento ${ }^{68} \mathrm{La}$ Corte reflexiona de la siguiente manera:

" $2^{\circ}$ ) Que, entonces, cabe preguntarse ¿están comprometidos los intereses generales de los consumidores por el reclamo hecho por una consumidora que por un error de la denunciada se le reservó en Recife, Brasil, en el Hotel Best Western Plus Viva Porto de Galinhas en

\footnotetext{
${ }^{61}$ Corte de Apelaciones de Concepción, 7 de agosto de 2015, Rol № 494-2015, Id. Vlex 579880238.

${ }^{62}$ Corte de Apelaciones de Talca, 21 de agosto de 2015, Rol N² 24-2015, Id. LP CL/JUR/4770/2015.

${ }^{63}$ Corte de Apelaciones de Santiago, 3 de diciembre de 2015, Rol 1359-2015, Id. Vlex 644248793; Corte de Apelaciones de Santiago, 14 de diciembre de 2015, Rol N 1220-2015, Id. MJ MJJ43192.

${ }^{64}$ Corte de Apelaciones de Santiago, 24 de diciembre de 2015, Rol N ${ }^{\circ} 1361-2015$, Id. LP CL/ JUR/8065/2015.

${ }^{65}$ Corte de Apelaciones de Santiago, 17 de junio de 2016, Rol N 277-2016, Id. Vlex 646975401.

${ }^{66}$ Corte de Apelaciones de Santiago, 28 de septiembre de 2016, Rol № 1164-2016, Id. MJ MJJ45893.

${ }^{67}$ Corte de Apelaciones de Santiago, 14 de diciembre de 2016, Rol N 287-2016, Id. LP CL/ JUR/8341/2016.

${ }^{68}$ Corte de Apelaciones de Santiago, 24 de abril de 2015, Rol No 1078-2014, Id. LP CL/JUR/2282/2015.
} 
circunstancias que debió haber sido hecha en el Hotel Best Western Solar Porto de Galinhas? Ciertamente no. Y no sólo porque se trata de una sola consumidora afectada, lo que ya sería suficiente para entender que los "intereses generales de los consumidores" no están comprometidos, sino porque de ninguna manera se ha demostrado en el proceso que exista una habitualidad en la conducta atribuida a la denunciada, esto es, que en otros muchos y determinados casos Lan Tours ha actuado negligentemente tomando reservas en hoteles distintos de aquellos pagados por el consumidor.

$3^{\circ}$ ) Que aun cuando el concepto "interés general de los consumidores" no está descrito en la ley, habrá que darle un sentido que permita determinar si SERNAC puede o no "hacerse parte" en procesos judiciales. No se trata, ciertamente, del interés colectivo o difuso de los Consumidores en que la ley 19.946 ha establecido un procedimiento especial en sus artículos 51 a 54 G. Es un interés distinto el de la letra g) del artículo 58 de la citada ley, uno que abstractamente involucra a la generalidad de los consumidores, a la "sociedad toda" como ha dicho alguna jurisprudencia y cobra relevancia nuevamente la pregunta: ¿afecta a la "sociedad toda", a los intereses de la generalidad de los que consumimos el que Lan Tours se haya equivocado en la reserva de un hotel reservando en uno distinto, hoteles cuyos nombres, por lo demás, son muy similares y claramente son de la misma cadena? Pues se piense lo que se piense sobre qué es lo que habrá querido decir el legislador con aquello del "interés general de los consumidores", lo cierto es que no se vislumbra como el problema, relativamente menor, que afectó a una consumidora y que no aparece que sea la conducta inveterada de Lan Tours el equivocarse de hotel, pueda comprometer "los intereses generales de los consumidores". Luego, SERNAC no tiene legitimación activa para hacerse parte en estos autos".

\section{LAS FACULTADES DEL SERNAC}

Por supuesto el SERNAC tiene un conjunto de facultades en la tutela de los intereses generales de los consumidores que no tiene demasiado sentido discutir. Por lo pronto, hacerse parte en las causas que están comprometidos como lo dispone expresamente la letra g) del artículo 58. Creemos que tampoco es discutible que debe formular programas de educación e información al consumidor, realizar investigaciones en áreas del consumo que lo comprometan, etc.

La discusión respecto a las facultades del SERNAC que se ha presentado ante los tribunales superiores chilenos no tiene nada que ver con esto, sino 
más bien con la facultad del SERNAC de demandar en juicio en tutela del interés general de los consumidores. La sentencia de la Corte de Apelaciones de Santiago de 14 de agosto de 2013, ${ }^{69}$ formula dicha cuestión de una forma particularmente elocuente:

“(...) en consecuencia, el asunto a dilucidar es si el SERNAC se encuentra habilitado procesalmente para denunciar en representación de los consumidores, una infracción a la ley antes referida, conforme a su artículo 58 letra g)". ${ }^{70}$

Creemos que frente a esta pregunta existen dos posturas. Denominamos a la primera minoritaria y, a la segunda, mayoritaria.

\subsection{La tendencia minoritaria}

Según la tendencia minoritaria, en la Ley 19.496 no existe algo así como una acción destinada a la tutela del interés general cuyo titular sea el SERNAC.

En algunas ocasiones los tribunales lo han dicho de maneraparticularmente explícita. En este sentido, puede recordarse, la opinión de la Corte Suprema en la sentencia con la que iniciamos este trabajo fue la siguiente:

"(...) las acciones judiciales destinadas a resguardar los derechos de los consumidores sólo pueden ejercerse a título individual o en beneficio del interés colectivo o difuso de aquellos.

En consecuencia, no existe en la legislación una cuarta categoría de acciones, como las de interés general que propone el Servicio Nacional del Consumidor..."

La misma Corte Suprema en sentencia del 25 de agosto de 2011, ${ }^{71}$ acogió un recurso de queja promovido por el Instituto Profesional AIEP S.A. en contra de la sentencia dictada por la Corte de Apelaciones de Santiago que acogió una querella infraccional fundada en la vulneración del interés público de los consumidores afectados por la publicidad engañosa de la carrera profesional de perito criminalista, resolviendo que:

"DUODECIMO: Que en la especie la demanda interpuesta por el Servicio Nacional del Consumidor, de conformidad con el artículo 51, $\mathrm{N}^{\mathrm{o}} 1^{\circ}$,

\footnotetext{
${ }^{69}$ Corte de Apelaciones de Santiago, 14 de agosto de 2013, Rol № 291-2013, Id. LP CL/JUR/1830/2013.

${ }^{70}$ Se repite la misma formulación en la sentencia de la Corte de Apelaciones de Santiago, 14 de agosto de 2013, Rol N² 290-2013, Id. MJ MJJ35834.

${ }^{71}$ Corte Suprema, 25 de agosto de 2011, Rol 4941-2011, Id. LP CL/JUR/6841/2011.
} 
letra a), en concordancia con el artículo 58, letra g) e inciso penúltimo, asumiendo la defensa de consumidores indeterminados, cuyos intereses generales denuncia comprometidos, incorpora la cuestión en el ámbito de los intereses difusos al margen de la exigencia contemplada en el artículo 51, $\mathrm{N}^{\mathrm{o}} 1$, letra c), en cuanto requiere un grupo de consumidores afectados en número no inferior a cincuenta personas debidamente individualizadas, y justamente, merced a esa indeterminación y características propias, lo sustrae de la norma común de competencia del juez de policía local, para entregarlo al conocimiento del juez civil ordinario, de acuerdo a las reglas generales".

En la misma sentencia el Ministro don Rubén Ballesteros Cárcamo concurre a la decisión sosteniendo que:

" $2{ }^{\circ}$ Que de lo relacionado se colige que las acciones judiciales destinadas a resguardar los derechos de los consumidores sólo pueden ejercerse a título individual o en beneficio del interés colectivo o difuso de aquellos. En consecuencia, no existe en la legislación una cuarta categoría de acciones, como las de interés general que propone el Servicio Nacional del Consumidor, pues si bien el artículo 58 letra $\mathrm{g}$ ) inciso $2^{\mathrm{a}}$ de la Ley $\mathrm{N}^{\mathrm{a}} 19.496$ dispone que la facultad de dicho servicio de velar por el cumplimiento de normas establecidas en leyes especiales que digan relación con el consumidor, incluye la atribución de denunciar los posibles incumplimientos ante los organismos o instancias jurisdiccionales respectivos y de hacerse parte en las causas en que estén afectados los intereses generales de los consumidores, la misma norma indica expresamente que ello debe hacerse "según los procedimientos que fijan las normas generales o los que se señalen en esas leyes especiales".

Por lo demás, la conclusión guarda relación y total armonía con el hecho de que la ley en examen sólo contempla dos tipos de procedimientos judiciales, el destinado a la protección del interés individual de los consumidores y el regulado en forma especial para la protección del interés colectivo o difuso de los consumidores.

La idea de que no existe una cuarta acción-de interés general-en la Ley 19.496 se encuentra también en la sentencia del 21 de diciembre de 2010, de la Corte de Apelaciones de Santiago, ${ }^{72}$ la de 3 de junio de 2013 de la Corte de

${ }^{72}$ Corte de Apelaciones de Santiago, 21 de diciembre de 2010, Rol º 2641-2010, Id. Vlex 233710651. 
Apelaciones de Concepción sobre sustracción de especies de un vehículo, ${ }^{73}$ la de 12 de diciembre de 2013 de la Corte de Apelaciones de Santiago, ${ }^{74}$ de 23 de diciembre de ese mismo Tribunal, ${ }^{75}$ de 2 de mayo de 2014 de la Corte de Apelaciones de Talca, ${ }^{76}$ de 8 de abril de 2015 de la Corte de Apelaciones de Concepción. ${ }^{77}$

Una manifestación más oblicua de esta tendencia minoritaria se encuentra en sentencias que, reconociendo un interés general de los consumidores comprometido, consideran que éste se encuentra tutelado por acciones de interés difuso. De esta manera, la ya citada sentencia de la Corte de Apelaciones de Concepción de 1 de abril de $2008,{ }^{78}$ consideró que el interés general de los consumidores estaba cautelado en la acción por interés difuso al señalar que:

" $5^{\circ}$ ) Que estos sentenciadores concuerdan en que la acción intentada en estos autos corresponde a las de interés difuso, puesto que, como se dijo en el motivo primero de este fallo, el Servicio denunciante expresó que la conducta del proveedor ha afectado los intereses generales de los consumidores (...)".

De esta manera, la Corte consideró que el Juzgado de Policía Local ante el cual se había presentado la denuncia resultaba incompetente.

Recogiendo este razonamiento, la Corte Suprema,${ }^{79}$ tres años después resolvió que:

"DUODECIMO: Que en la especie la demanda interpuesta por el Servicio Nacional del Consumidor, de conformidad con el artículo 51, $\mathrm{N}^{\circ} 1^{\circ}$, letra a), en concordancia con el artículo 58, letra g) e inciso penúltimo, asumiendo la defensa de consumidores indeterminados, cuyos intereses generales denuncia comprometidos, incorpora la cuestión en el ámbito

${ }^{73}$ Corte de Apelaciones de Concepción, 3 de junio de 2013, Rol № 78-2013, Id. Vlex 642353149.

${ }^{74}$ Corte de Apelaciones de Santiago, 12 de diciembre de 2013, Rol No 1609-2013, Id. Vlex 56349274. De manera bastante sorprendente, la misma Corte de Apelaciones de Santiago, 16 de diciembre de 2013, Rol No 1777-2013, Id. Vlex 571530102 resuelve que el artículo 58 letra g) de la Ley 19.496 faculta al Servicio para accionar.

${ }^{75}$ Corte de Apelaciones de Santiago, 23 de diciembre de 2013, Rol No 2273-2013, Id. Vlex 586479850. Sin embargo, la misma Corte de Apelaciones de Santiago, 8 de enero de 2014, Rol No 1814-2013, Id. Vlex 567324766, vuelve a reconocer a SERNAC la posibilidad de accionar.

${ }^{76}$ Corte de Apelaciones de Talca, 2 de mayo de 2014, Rol N²682-2013, Id. LP CL/JUR/1994/2014.

${ }_{77}$ Corte de Apelaciones de Concepción, 8 de abril de 2015, Rol № 41-2014, Id. Vlex 577682150.

${ }^{78}$ Corte de Apelaciones de Concepción, 1 de abril de 2008, Rol No 2054-2005, Id. LP CL/ JUR/5632/2008.

${ }^{79}$ Corte Suprema, 25 de agosto de 2011, Rol 4941-2011, Id. LP CL/JUR/6841/2011. 
de los intereses difusos al margen de la exigencia contemplada en el artículo $51, \mathrm{~N}^{\circ} 1^{\circ}$, letra c), en cuanto requiere un grupo de consumidores afectados en número no inferior a cincuenta personas debidamente individualizadas, y justamente, merced a esa indeterminación y características propias, lo sustrae de la norma común de competencia del juez de policía local, para entregarlo al conocimiento del juez civil ordinario, de acuerdo a las reglas generales".

Por tal razón y al igual que el fallo anterior, la Corte Suprema consideró que el juez de Policía Local era incompetente para conocer de la acción, declarando su incompetencia.

Una tercera manifestación de esta tendencia minoritaria consiste en negar la existencia de un interés general cuando existe uno colectivo involucrado. De esta manera, la sentencia de la Corte de Apelaciones de Santiago de 12 de junio de $2012,{ }^{80}$ resuelve una denuncia por el cambio unilateral de fecha de un concierto, y consideró que no existía un interés general comprometido allí, sino uno colectivo, declarando incompetente al Juzgado de Policía Local.

En fin, en una sentencia de la Corte de Apelaciones de Antofagasta del 17 de enero de $2013,{ }^{81}$ la confusión alcanza su mayor grado, en los siguientes términos:

“(...) el artículo 58 letra g) de la Ley del Consumidor expresa que el Servicio debe velar por el cumplimiento de las disposiciones reglamentarias relacionadas con la protección de los derechos de los consumidores y hacerse parte en aquellas causas que comprometan los intereses generales de los consumidores, lo que se traduce en que el Servicio Nacional del Consumidor tiene la posibilidad de comparecer en un proceso por vía principal, es decir ejerciendo la respectiva acción individual ante el Juez de Policía Local, colectiva o difusa ante los Tribunales Ordinarios (...)".

\subsection{La tendencia mayoritaria}

La abrumadora mayoría de las decisiones de las Cortes de Apelaciones considera que el artículo $58 \mathrm{~g}$ ) concede al SERNAC una acción autónoma y diversa de las acciones de interés individual e intereses colectivos y difusos.

\footnotetext{
${ }^{80}$ Corte de Apelaciones de Santiago, 12 de junio de 2012, Rol N 1781-2011, Id. LP CL/JUR/1086/2012.

${ }^{81}$ Corte de Apelaciones de Antofagasta, 17 de enero de 2013, Rol No 214-2012, Id. MJ MJJ34373
} 
Se trata de una tendencia que encontramos ya en una sentencia de la Corte de San Miguel del 2 de junio de 2009, ${ }^{82}$ y se mantiene hasta una de la Corte de Apelaciones de Santiago del 17 de marzo de 2017. ${ }^{83}$

Aunque las sentencias son demasiadas para citarlas, ${ }^{84}$ queremos comenzar citando algunas que ilustran con particular elocuencia esta segunda tendencia. La primera de ellas corresponde a una de la Corte de Apelaciones de Temuco de 2 de marzo de 2012, ${ }^{85}$ que conociendo de una acción del SERNAC fundada en el artículo $58 \mathrm{~g}$ ) por supuesta publicidad engañosa, sostuvo:

"Que es correcta la alegación del Servicio Nacional del Consumidor en orden a que deben ser claramente distinguidas las acciones colectivas, las acciones difusas y las acciones de interés general, de modo que ninguna de ellas se identifica o coincide con alguna de las otras.

En efecto, el ya citado artículo 50 distingue tres clases de acciones, atendiendo a los sujetos afectados: las acciones individuales, las acciones de interés colectivo y las acciones de interés difuso.

Por otra parte, una categoría distinta de clasificación de las acciones contempladas en la ley 19.496 atiende al interés afectado. En tal sentido se distingue entre acciones en las que se encuentra afectado el interés singular de uno o más consumidores y acciones en las que se encuentra afectado el interés general de los consumidores.

Aunque existen otras clasificaciones, las mencionadas son las únicas relevantes a efectos de la presente decisión.

Pues bien, puede ocurrir que una acción individual sea simultáneamente una acción en la que esté involucrado el interés general, y que una acción de interés público sea al mismo tiempo una acción en la que esté afectado el interés singular de varios consumidores (pero no el interés general). Esto es tan evidente como que el acto jurídico en materia civil admite diversas clasificaciones, y que un determinado acto jurídico puede ser caracterizado simultáneamente bajo las diversas clasificaciones. Así, por ejemplo, la compraventa es un acto jurídico bilateral, oneroso y entre vivos. Esto es lo que explica que la facultad otorgada al Servicio Nacional del Consumidor en el ya mencionado artículo 58, letra g),

${ }^{82}$ Corte de Apelaciones de San Miguel, 2 de junio de 2009, Rol N³19-2009, Id. LP CL/JUR/8305/2009.

${ }^{83}$ Corte de Apelaciones de Concepción, 27 de marzo 2017, Rol № 64-2017, Id. Vlex 672259117.

${ }^{84}$ Sin embargo, en este apartado se citarán suficientes como para acreditarlo. Con todo, podemos decir que de las 181 sentencias que revisamos, únicamente 16 desconocían la facultad del SERNAC de denunciar por el interés general de los consumidores.

${ }^{85}$ Corte de Apelaciones de Temuco, 2 de marzo de 2012, Rol No 109-2011, Id. Vlex 573022446. 
pueda aplicarse respecto de acciones individuales, de interés colectivo o de interés difuso, pues lo único que importa al efecto es que se encuentre afectado el interés general de los consumidores.

El reconocimiento de diversas categorías de clasificación de las acciones procesales, que la doctrina procesal califica de actos jurídicos procesales, en el caso de las acciones contempladas en la ley 19.496 no es, sin embargo, relevante para efectos de resolver el presente caso, desde que la única categoría que considera el ya mencionado artículo 50 A para definir la competencia absoluta es la de los sujetos afectados".

En el mismo sentido, la Corte de Apelaciones de San Miguel en sentencia de 21 de marzo de $2012^{86}$ resolvió que:

"Octavo: Que en conclusión, existe una diferencia entre los intereses de clase como los colectivos y difusos por un lado y, de otro, los intereses generales que han de ser cautelados por instituciones públicas del carácter del Servicio Nacional del Consumidor, cuyo fin es "velar por el cumplimiento de las disposiciones legales y reglamentarias relacionadas con la protección de los consumidores y hacerse parte en aquellas causas que comprometan los intereses generales de los consumidores...".

Existe la competencia cuando los intereses perseguidos, sean individuales o colectivos, se encuentren "determinados" y no "difusos", o sea, cuando no sean vagos ni imprecisos.

En fin, el mismo tribunal, el 18 de mayo de $2015,{ }^{87}$ falló en idéntico sentido al considerar lo siguiente:

" $7^{\circ}$. Que se desprende, así, que existe una diferencia entre los intereses de clase como los colectivos y difusos por un lado y, de otro, los intereses generales que han de ser cautelados por instituciones públicas del carácter del Servicio Nacional del Consumidor, cuyo fin es "velar por el cumplimiento de las disposiciones de la presente ley y demás normas que digan relación con el consumidor".

No sólo se contemplan en la ley 19.496, entonces, acciones de "intereses colectivos o difusos", sino también acciones de cesación definidas como "las que se encaminan a lograr que no se siga realizando una determinada actividad. Se trata, en el fondo, de verdaderas obligaciones

\footnotetext{
${ }^{86}$ Corte de Apelaciones de San Miguel, 21 de marzo de 2012, Rol No 106-2012, Id. LP CL/ JUR/681/2012.

${ }^{87}$ Corte de Apelaciones de San Miguel, 18 de mayo de 2015, Rol № 760-2015, Id. Vlex 571428682.
} 
de no hacer impuestas jurisdiccionalmente. La existencia de las acciones de cesación nace de considerar que en muchas conductas lesivas a los consumidores se producen situaciones de peligro que justifiquen la intervención jurisdiccional, para evitar que ese riesgo se traduzca en un daño efectivo" (A.R.S. obra citada página 323).

$8^{\circ}$. Que, como se observa, existe una diferencia de lo que se entiende por intereses colectivos o difusos y la facultad que permite a un órgano fiscalizador público denunciar ciertos hechos presuntamente contravencionales cuyo objeto no persigue estrictamente cautelar un interés de clase concreto y manifiesto perteneciente a un grupo de consumidores, sino que trasciende a la salvaguarda de intereses que van más allá de aquellos, aunque indirectamente tiene incidencia en los derechos de los consumidores."

Estas decisiones, a diferencia de las anteriores, rechazan incidentes de falta de legitimidad activa del SERNAC, o de incompetencia absoluta, promovidos por el proveedor denunciado, lo que en definitiva conlleva a una construcción jurisprudencial de una cuarta categoría de acciones: la de interés general.

Pues bien, una primera cosa que nos interesa subrayar de esta acción de interés general es que su titularidad pertenece al SERNAC. Así una sentencia de la Corte de Apelaciones de Puerto Montt de 4 de mayo de 2015, ${ }^{88}$ indica que: "...como lo ha señalado en forma reiterada la Jurisprudencia de nuestros Tribunales Superiores de Justicia, solo compete al Servicio Nacional del Consumidor presentar denuncias o hacerse parte, cuando en las causas se comprometan los intereses generales de los consumidores (artículo 58 de la Ley 19.496) y el artículo 50 en su inciso tercero de dicha Ley, se señala que "El ejercicio de las acciones puede realizarse a título individual o en beneficio del interés colectivo o difuso de los consumidores", lo cual hace entender que entonces el SERNAC para esas situaciones cuenta con habilitación procesal para ejercer las acciones que la ley le ha señalado".

La segunda cuestión que queremos advertir es que las Cortes de Apelaciones no sólo le han reconocido al SERNAC su titularidad respecto de la acción de interés general, sino que, además, han enfatizado su importancia. De esta manera, en ocasiones han señalado que se trataría de una "función esencial" del SERNAC. Así, por ejemplo, en la sentencia de la Corte de

${ }^{88}$ Corte de Apelaciones de Puerto Montt, 4 de mayo de 2015, Rol № 16-2015, Id. Vlex 569848690. 
Apelaciones de San Miguel de 9 de enero de 2013, ${ }^{89}$ se lee lo siguiente:

"Que conforme al texto de las disposiciones legales antes citadas se puede colegir que al Servicio le asiste como función esencial el velar por la protección de los derechos de los consumidores, y dentro de este entendido es menester que cuente con la habilitación procesal necesaria para ejercer las acciones que le permitan cumplir con la función que el legislador ha puesto bajo su amparo. El interpretarlo de modo diverso significaría que en la práctica el Servicio se vería impedido de ejercer de la debida forma con la función que la ley le ha entregado, transgredido la intención que el legislador tuvo en cuenta para establecer una normativa protectora y cautelar de los derechos de los consumidores"..$^{90}$

En otras ocasiones se han referido a una "función inherente" como la denomina la sentencia de la Corte de Apelaciones de San Miguel del 22 de marzo de 2013. ${ }^{91}$ En otras sentencias, las Cortes de Apelaciones han sido aún más enfáticas, señalando que el SERNAC tiene un "deber legal" de denunciar las infracciones que comprometen el interés general de los consumidores. Así, por ejemplo, en la sentencia de la Corte de Apelaciones de Valdivia del 2 de febrero de $2015,{ }^{92}$ se lee lo siguiente:

"De la norma transcrita queda establecido que el Servicio Nacional del Consumidor tiene el deber legal de denunciar los posibles incumplimientos ante las instancias jurisdiccionales respectivas, en que estén afectados los intereses generales de los consumidores, de manera que al denunciar los hechos que ha reputado contravienen derechos de los consumidores, el SERNAC ha actuado en la esfera de las atribuciones

\footnotetext{
${ }^{89}$ Corte de Apelaciones de San Miguel, 9 de enero de 2013, Rol N 1135-2012, Id. Vlex 643806685.

${ }^{90}$ En el mismo sentido puede consultarse sentencia de la Corte de Apelaciones de San Miguel, 24 de octubre de 2012, Rol N 1098-2012, Id. Vlex 405272022; Corte de Apelaciones de Santiago, 25 de junio de 2013, Rol No 1389-2012, Id. LP CL/JUR/1394/2013; Corte de Apelaciones de Santiago, 14 de agosto de 2013, Rol N²91-2013, Id. LP CL/JUR/1830/2013; Corte de Apelaciones de Santiago, 9 de agosto de 2013, Rol N 181-2013, Id. LP CL/JUR/1855/2013; Corte de Apelaciones de San Miguel, 30 de septiembre de 2013, Rol N 1312-2013, Id. Vlex 572917562; Corte de Apelaciones de Santiago, 20 de agosto de 2014, Rol N²147-2013, Id. Vlex 577716522; Corte de Apelaciones de Santiago, 28 de noviembre de 2014, Rol N 885-2014, Id. MJ MJJ39637; Corte de Apelaciones de Rancagua, 1 de abril de 2016, Rol N 136-2015, Id. LP CL/JUR/2357/2016; Corte de Apelaciones de Santiago, 30 de abril de 2015, Rol N 108-2015, Id. LP CL/JUR/2399/2015; Corte de Apelaciones de Santiago, 28 de septiembre de 2016, Rol N 1164-2016, Id. MJ MJJ45893; Corte de Apelaciones de Santiago, 3 de noviembre de 2016, Rol N 1294-2016, Id. LP 653216493.

${ }^{91}$ Corte de Apelaciones de San Miguel, 22 de febrero de 2013, Rol No 100-2013, Id. Vlex 488402558.

${ }^{92}$ Corte de Apelaciones de Valdivia, 2 de febrero de 2015, Rol N 179-2014, Id. LP CL/JUR/535/2015.
} 
que legalmente le han sido conferidas". ${ }^{93}$

En fin, estas ideas, probablemente, pueden engancharse con otra que es posible encontrar en algunas de las sentencias, que utilizan la historia fidedigna de la Ley 19.955, que fue la que introdujo el artículo 58 para justificar la habilitación procesal del SERNAC.${ }^{94}$ Así, por ejemplo, en una sentencia de la Corte de Apelaciones de San Miguel de 3 de mayo de 2013 se lee lo siguiente:

"Que, sin duda la Ley de Protección del Consumidor ha ampliado la legitimación del Servicio denunciante para que pueda ejercer la adecuada defensa de los intereses de los consumidores, esto lo señaló expresamente el mensaje del Presidente de la república, al proyecto que modificó la Ley 19.496, al señalar que se pretende "crear mecanismos para que la relación de consumo funcione correctamente... y se aumenta el alcance de las atribuciones del Servicios Nacional del Consumidor".

Una tercera cuestión que nos interesa comentar se refiere a la función que las Cortes de Apelaciones han reconocido a esta acción de interés general. Respecto de esta pregunta, la sentencia de la Corte de Apelaciones de Temuco del 30 de julio de 2012, resulta particularmente elocuente:

“(...) el objeto principal de las acciones de interés colectivo o difuso, es la indemnización de los perjuicios sufridos por los consumidores afectados o la declaración de nulidad de cláusulas abusivas, en cambio en el caso de la acción en interés general (cuyo único legitimado activo es el SERNAC) el objeto es la sanción del proveedor, que con su conducta ha infringido normas de la ley 19.496, que afectan el mencionado interés general de los consumidores.

En efecto, la defensa del interés general, no conlleva avalar derechos subjetivos, como sí ocurre con acciones de interés colectivo o difuso, que pueden conllevar pago de indemnizaciones a los consumidores, únicamente avala intereses públicos, que en el caso del art. 58 letra g) se expresa en el ejercicio de la actividad de policía administrativa que

\footnotetext{
${ }^{93}$ En el mismo sentido, es decir reconociendo un deber a SERNAC en tal tendencia, ver sentencia de la Corte de Apelaciones de Santiago, 31 de agosto de 2015, Rol N 822-2015, Id. LP CL/JUR/4968/2015.

${ }^{94}$ Así, por ejemplo, Corte de Apelaciones de Santiago, 23 de junio de 2010, Rol No 904-2010, Id. Vlex 233685551; Corte de Apelaciones de Temuco, 30 de julio de 2012, Rol № 92-2012, Id. LP CL/ JUR/1531/2012; Corte de Apelaciones de Santiago, 2 de octubre de 2013, Rol № 626-2013, Id. Vlex 586480246; Corte de Apelaciones de Santiago, 25 de marzo de 2013, Rol N ${ }^{\circ}$ 916-2012, Id. Vlex 631982545; Corte de Apelaciones de San Miguel, 18 de mayo de 2015, Rol No 761-2015, Id. Vlex 571428686.
} 
cabe al SERNAC entendida ésta como el medio por el cual se manifiesta el poder público de la administración de una forma coercitiva, a través del estado; limitando los derechos y libertades en beneficio del bienestar general o bien común a través de la amenaza y de la coacción (la sanción administrativa)". 95

La cuarta cuestión que nos interesa considerar aquí se refiere a las condiciones de procedencia de esta acción, específicamente el hecho de que no existan causas pendientes a las que hacerse parte. Lo que descubrimos es que se ha fallado que la denuncia incoada por el Sernac resulta suficiente para iniciar una causa. ${ }^{96}$

La quinta cuestión que nos ocupa se refiere a la competencia absoluta tratándose de esta acción. Y sobre el tema se ha fallado con gran frecuencia que su conocimiento corresponde a los Juzgados de Policía Local. ${ }^{97}$

${ }^{95}$ Corte de Apelaciones de Temuco, Rol No 92-2012, 30 de julio de 2012, Id. LP CL/JUR/1531/2012. Por su parte, la sentencia de la Corte de Apelaciones de Santiago, 14 de diciembre de 2016, Rol N ${ }^{\circ} 287-2016$, Id. Vlex CL/JUR/8341/2016, indica que el interés general "abarca el beneficio de la sociedad política, utilizándose generalmente como sinónimo de interés público o bien común". V. Corte de Apelaciones de Temuco, 2 de octubre de 2012, Rol N 118-2012, Id. Vlex 403150278; Corte de Apelaciones de Santiago, 25 de junio de 2013, Rol N 1389-2012, Id. LP CL/JUR/1394/2013; Corte de Apelaciones de Santiago, 14 de agosto de 2013, Rol № 291-2013, Id. LP CL/JUR/1830/2013; Corte de Apelaciones de Santiago, 19 de agosto de 2013, Rol N 181-2013, Id. LP CL/JUR/1855/2013; Corte de Apelaciones de Santiago, 3 de abril de 2014, Rol No 1867-2013, Id. LP CL/JUR/858/2014; Corte de Apelaciones de Santiago, 20 de agosto de 2014, Rol ํ 2147-2013, Id. Vlex 577716522; Corte de Apelaciones de Santiago, 4 de septiembre de 2014, Rol N ${ }^{\circ}$ 538-2014, Id. Vlex 581381766; Corte de Apelaciones de Santiago, 5 de enero de 2015, Rol N 1403-2014, Id. MJ MJJ40061; Corte de Apelaciones de Santiago, 30 de enero de 2015, Rol No 1523-2014, Id. MJ MJJ4042; Corte de Apelaciones de Santiago, 13 de mayo de 2015, Rol N 92-2015, Id. Vlex 569854154; Corte de Apelaciones de San Miguel, 2 de junio de 2015, Rol N 758-2015, Id. MJ MJJ41918.

${ }_{96}$ Ver, por ejemplo, sentencia de la Corte de Apelaciones de San Miguel, 5 de abril de 2013, Rol № 182-2013, Id. Vlex 644906685; Corte de Apelaciones de Santiago, 6 de enero de 2015, Rol № 14642014, Id. Vlex 591278530; Corte de Apelaciones de Valdivia, 10 de julio de 2015, Rol N 102-2015, Id. Vlex 577716202; Corte de Apelaciones de Valdivia, 31 de julio de 2015, Rol N 132-2015, Id. LP CL/JUR/4396/2015.

${ }_{97}$ Ver, por ejemplo, Corte de Apelaciones de Santiago, 17 de octubre de 2012, Rol № 2642-2011, Id. Vlex 563532850; Corte de Apelaciones de Punta Arenas, 24 de enero de 2013, Rol N 245-2012, Id. Vlex 634692185; Corte de Apelaciones de Santiago, 13 de marzo de 2013, Rol № 1045-2012, Id. Vlex 579583294; Corte de Apelaciones de Santiago, 6 de junio de 2013, Rol № 1457-2012, Id. Vlex 643820197; Corte de Apelaciones de Santiago, 12 de junio de 2012, Rol № 1781-2011, Id. LP CL/JUR/1086/2012; Corte de Apelaciones de Santiago, 10 de julio de 2013, Rol N ${ }^{\circ} 1715-2012$, Id. MJ MJJ39147; Corte de Apelaciones de Santiago, 7 de agosto de 2013, Rol № 137-2013, Id. Vlex 456025818; Corte de Apelaciones de Santiago, 18 de diciembre de 2013, Rol N 1602-2013, Id. Vlex 563442198 . 


\section{CONCLUSIONES}

Deseamos concluir, en primer lugar, recordando las hipótesis. En segundo lugar, calibrando su corrección.

Por lo que toca a las hipótesis, son dos, a saber: (1) no obstante la grandilocuencia de la definición de interés general, la aplicación del concepto por parte de los tribunales enseña que este se ocupa prácticamente en cualquier situación; (2) las Cortes de Apelaciones, de manera abrumadoramente mayoritaria, se han pronunciado de forma contradictoria a la Corte Suprema, asumiendo que existe una acción destinada a tutelar los intereses generales de los consumidores, cuyo titular es el SERNAC.

Pues bien, respecto de la primera hipótesis, confiamos en haber demostrado que si se presta atención a cómo definen las Cortes los intereses generales aparece como si fuera algo que concierne a la sociedad en su conjunto. Sin embargo -y esta es una segunda conclusión- creemos haber demostrado que esa definición no suele compadecerse con la práctica de las Cortes de Apelaciones. Al observar sus sentencias aprendemos que toda clase de asuntos, con independencia de si afectan o no a la sociedad en su conjunto, pueden ser objeto de una acción destinada a tutelar el interés general de los consumidores. Salvo, por su puesto, que se acepte que cualquier infracción a la Ley 19.496 potencialmente afecta el interés general de los consumidores. El punto es que una comprensión tan desmesuradamente amplia diluye el pretendido carácter distintivo de las acciones de interés general, confundiéndolas con las de interés individual. Y aquí podemos añadir que las Cortes estiman que el conocimiento de esta acción pertenece a los Juzgados de Policía Local.

Por lo que toca a la segunda hipótesis, nos parece que hemos acreditado que la gran mayoría de las sentencias de las Cortes de Apelaciones estiman que existe una acción distinta a las de interés individual, colectivo y difuso, cuyo objetivo es la tutela de los intereses generales de los consumidores. Igualmente, nos parece que las sentencias estiman consistentemente que el SERNAC es el titular de esta acción. De hecho, con cierta frecuencia entienden que la historia fidedigna del establecimiento del artículo 58 letra g) así lo indica y consideran que si se le privara de la posibilidad de denunciar por interés general se le impediría realizar esta función.

\section{BIBLIOGRAFÍA CITADA}

Barrientos Camus, Francisca (coord.), Condiciones generales de la contratación y cláusulas abusivas, Ediciones de la Universidad Diego Porta- 
les, Santiago, 2014.

Carrasco Poblete, Jaime, "La legitimación activa y extraordinaria del SERNAC para velar por los intereses generales de los consumidores", en Barrientos Camus, Francisca (coord.), Condiciones generales de la contratación y cláusulas abusivas, Ediciones de la Universidad Diego Portales, Santiago, 2014, pp. 331-348.

De la Maza Gazmuri, Iñigo; Pizarro Wilson, Carlos (dirs.), La protección de los consumidores, Thomson Reuters, Santiago, 2013.

Fernández Fredes, Francisco, "Nueva ley del consumidor: innovaciones y limitaciones", Revista Perspectivas, 1998, vol. 1, No 2, p. 122 ss.

Isler Soto, Erika, "Comentario artículo 58" en De la Maza Gazmuri, Iñigo; Pizarro Wilson, Carlos (Dirs.), La protección de los consumidores, Thomson Reuters, Santiago, 2013, pp. 1148-1150.

Momberg Uribe, Rodrigo, "La autonomía de la acción en interés general de los consumidores del artículo 58 letra g) de la Ley No 19.496 sobre protección de los derechos de los consumidores (LPC) (Corte Suprema)", Revista de Derecho (Valdivia), 2011, vol. XXIV No 2, pp. 235-244.

Poblete Iturrate, Orlando, "Las acciones por intereses colectivos y difusos. Algunas consideraciones básicas", Revista de Derecho Universidad Finis Terrae, 2003, VII, No 7, p. 283.

\section{JURISPRUDENCIA CITADA}

Corte de Apelaciones de Concepción, 1 de abril de 2008, Rol No 2054-2005, Id. LP CL/JUR/5632/2008.

Corte de Apelaciones de San Miguel, 2 de junio de 2009, Rol N 319-2009, Id. LP CL/JUR/8305/2009.

Corte de Apelaciones de San Miguel, 29 de marzo de 2010, Rol N $124-$ 2010, Id. Vlex 226548731.

Corte de Apelaciones de Santiago, 23 de junio de 2010, Rol N 904-2010, Id. Vlex 233685551.

Corte Suprema, 27 de julio de 2010, Rol N² 2917-2010, Id. MJ MJJ24421.

Corte de Apelaciones de Concepción, 27 de octubre de 2010, Rol N 2732010, Id. MJ MJJ25391.

Corte de Apelaciones de Santiago, 21 de diciembre de 2010, Rol N ${ }^{\circ} 2641$ 2010, Id. Vlex 233710651.

Corte de Apelaciones de Concepción, 1 de marzo de 2011, Rol № 449-2010, Id. LP CL/JUR/1677/2011. 
Corte de Apelaciones de Iquique, 4 de mayo de 2011, Rol No 15-2011, Id. Vlex 275584931.

Corte Suprema, 25 de agosto de 2011, Rol 4941-2011, Id. LP CL/ JUR/6841/2011.

Corte de Apelaciones de Santiago, 30 de noviembre de 2011, Rol № $1264-$ 2011, Id. LP CL/JUR/8835/2011.

Corte de Apelaciones de Antofagasta, 6 de enero de 2012, Rol № 195-2011, Id. Vlex 563556822.

Corte de Apelaciones de Temuco, 2 de marzo de 2012, Rol № 109-2011, Id. Vlex 573022446.

Corte de Apelaciones de San Miguel, 21 de marzo de 2012, Rol No $106-$ 2012, Id. LP CL/JUR/681/2012.

Corte de Apelaciones de Santiago, 12 de junio de 2012, Rol № 1781-2011, Id. LP CL/JUR/1086/2012.

Corte de Apelaciones de Temuco, 30 de julio de 2012, Rol No 92-2012, Id. Vlex 395476190; Id. LP CL/JUR/1531/2012.

Corte de Apelaciones de Temuco, 2 de octubre de 2012, Rol № 118-2012, Id. Vlex 403150278.

Corte de Apelaciones de Santiago, 17 de octubre de 2012, Rol N ${ }^{\circ} 2642-$ 2011, Id. Vlex 563532850.

Corte de Apelaciones de San Miguel, 24 de octubre de 2012, Rol N ${ }^{\circ} 1098$ 2012, Id. Vlex 405272022.

Corte de Apelaciones de Santiago, 8 de noviembre de 2012, Rol N 22342011, Id. Vlex 573058030.

Corte de Apelaciones de Arica, 13 de diciembre de 2012, Rol N 51-2012, Id. Vlex 412708150.

Corte de Apelaciones de Concepción, 28 de diciembre de 2012, Rol N ${ }^{\circ}$ 203-2012, Id. Vlex 579585018.

Corte de Apelaciones de San Miguel, 9 de enero de 2013, Rol No 1135 2012, Id. Vlex 643806685.

Corte de Apelaciones de Antofagasta, 17 de enero de 2013, Rol No 2142012, Id. MJ MJJ34373.

Corte de Apelaciones de Punta Arenas, 24 de enero de 2013, Rol N 2452012, Id. Vlex 634692185.

Corte de Apelaciones de Punta Arenas, 24 de enero de 2013, Rol N ${ }^{\circ} 2445$ 2012, Id. Vlex 6346921185.

Corte de Apelaciones de San Miguel, 22 de febrero de 2013, Rol N 100 2013, Id. Vlex 488402558.

Corte de Apelaciones de Santiago, 13 de marzo de 2013, Rol № 1045-2012, Id. Vlex 579583294. 
Corte de Apelaciones de Santiago, 14 de marzo de 2013, Rol N 399-2012, Id. LP CL/JUR/845/2013.

Corte de Apelaciones de Santiago, 14 de marzo de 2013, Rol N 682-2012, Id. Vlex VLEX-632020661.

Corte de Apelaciones de Santiago, 15 de marzo de 2013, Rol № 176-2012, Id. Vlex 563495622.

Corte de Apelaciones de Santiago, 25 de marzo de 2013, Rol № 916-2012, Id. Vlex 631982545.

Corte de Apelaciones de San Miguel, 5 de abril de 2013, Rol № 182-2013, Id. Vlex 644906685.

Corte de Apelaciones de Santiago, 11 de abril de 2013, Rol N 1141-2012, Id. Vlex 579571038.

Corte de Apelaciones de Rancagua, 31 de mayo de 2013, Rol N 44-2013, Id. Vlex VLEX-586509838.

Corte de Apelaciones de Concepción, 3 de junio de 2013, Rol № 78-2013, Id. Vlex 642353149.

Corte de Apelaciones de Santiago, 6 de junio de 2013, Rol No 1457-2012, Id. Vlex 643820197.

Corte de Apelaciones de Santiago, 10 de junio de 2013, Rol N 400-2012, Id. Vlex 563462258.

Corte de Apelaciones de Santiago, 25 de junio de 2013, Rol N 1389-2012, Id. LP CL/JUR/1394/2013.

Corte de Apelaciones de Santiago, 15 de julio de 2013, Rol N 1779-2012, Id. Vlex 581436026.

Corte de Apelaciones de Santiago, 25 de junio de 2013, Rol N 1389-2012, Id. LP CL/JUR/1394/2013.

Corte de Apelaciones de Coyhaique, 8 de julio de 2013, Rol No 24-2013, Id. Vlex 637440973.

Corte de Apelaciones de Santiago, 10 de julio de 2013, Rol N 1715-2012, Id. MJ MJJ39147.

Corte de Apelaciones de Santiago, 7 de agosto de 2013, Rol N 137-2013, Id. Vlex 456025818.

Corte de Apelaciones de Santiago, 9 de agosto de 2013, Rol N 181-2013, Id. LP CL/JUR/1855/2013.

Corte de Apelaciones de Santiago, 14 de agosto de 2013, Rol N²91-2013, Id. LP CL/JUR/1830/2013.

Corte de Apelaciones de Santiago, 14 de agosto de 2013, Rol N 290-2013, Id. MJ MJJ35834.

Corte de Apelaciones de Santiago, 20 de agosto de 2013, Rol № 67-2013, Id. LP CL/JUR/1863/2013. 
Corte de Apelaciones de San Miguel, 30 de septiembre de 2013, Rol N ${ }^{\circ}$ 1312-2013, Id. Vlex 572917562.

Corte de Apelaciones de Santiago, 2 de octubre de 2013, Rol N 626-2013, Id. Vlex 586480246.

Corte de Apelaciones de Santiago, 9 de octubre de 2013, Rol № 951-2013, Id. Vlex 589950470.

Corte de Apelaciones de Santiago, 23 de octubre de 2013, Rol № 619-2013, Id. Vlex 586482642.

Corte de Apelaciones de Santiago, 28 de octubre de 2013, Rol No 1141 2013, Id. Vlex 637429565.

Corte de Apelaciones de Santiago, 30 de octubre de 2013, Rol N ${ }^{\circ} 1253$ 2013, Id. LP CL/JUR/2404/2013.

Corte de Apelaciones de Talca, 22 de noviembre de 2013, Rol № 714-2013, Id. Vlex 590006274.

Corte de Apelaciones de Santiago, 26 de noviembre de 2013, Rol No 15732013, Id. MJ MJJ36427.

Corte de Apelaciones de Coyhaique, 5 de diciembre de 2013, Rol № 372013, Id. Vlex 576767510.

Corte de Apelaciones de Antofagasta, 6 de diciembre de 2013, Rol No 131 2013, Id. MJ MJJ36768.

Corte de Apelaciones de Santiago, 12 de diciembre de 2013, Rol No 16092013, Id. Vlex 56349274.

Corte de Apelaciones de Santiago, 16 de diciembre de 2013, Rol No 17772013, Id. Vlex 571530102.

Corte de Apelaciones de Santiago, 18 de diciembre de 2013, Rol N ${ }^{\circ} 1602$ 2013, Id. Vlex 563442198.

Corte de Apelaciones de Santiago, 23 de diciembre de 2013, Rol № $2273-$ 2013, Id. Vlex 586479850.

Corte de Apelaciones de Santiago, 8 de enero de 2014, Rol No 1814-2013, Id. Vlex 567324766.

Corte de Apelaciones de San Miguel, 21 de marzo de 2014, Rol N ${ }^{\circ} 122-$ 2014, Id. LP CL/JUR/491/2014.

Corte de Apelaciones de Santiago, 3 de abril de 2014, Rol N 1867-2013, Id. LP CL/JUR/858/2014.

Corte de Apelaciones de Talca, 3 de abril de 2014, Rol N 3035-2013, Id. LP CL/JUR/871/2014.

Corte de Apelaciones de Santiago, 15 de abril de 2014, Rol N 792-2013, Id. LP CL/JUR/1353/2014.

Corte de Apelaciones de Santiago, 30 de abril de 2014, Rol N²087-2013, Id. LP CL/JUR/1866/2014. 
Corte de Apelaciones de Talca, 2 de mayo de 2014, Rol N²682-2013, Id. LP CL/JUR/1994/2014.

Corte de Apelaciones de Concepción, 9 de junio de 2014, Rol N² 294-2013, Id. Vlex VLEX-563435290.

Corte de Apelaciones de Santiago, 20 de agosto de 2014, Rol № 21472013, Id. Vlex 577716522.

Corte de Apelaciones de Santiago, 20 de agosto de 2014, Rol № 513-2014, Id. Vlex 579425090.

Corte de Apelaciones de Santiago, 4 de septiembre de 2014, Rol № 5382014, Id. Vlex 581381766.

Corte de Apelaciones de Concepción, 10 de septiembre de 2014, Rol $N^{\circ}$ 24-2014, Id. Vlex 577689646.

Corte de Apelaciones de Santiago, 25 de septiembre de 2014, Rol N ${ }^{\circ} 646-$ 2014, Id. Vlex 581341454.

Corte de Apelaciones de Santiago, 29 de octubre de 2014, Rol N 967-2014, Id. Vlex 582329050.

Corte de Apelaciones de Santiago, 30 de octubre de 2014, Rol N 765-2014, Id. LP CL/JUR/8014/2014.

Corte de Apelaciones de Valdivia, 19 de noviembre de 2014, Rol N $195-$ 2014, Id. Vlex 544709678.

Corte de Apelaciones de Santiago, 28 de noviembre de 2014, Rol No $885-$ 2014, Id. MJ MJJ39637.

Corte de Apelaciones de Santiago, 2 de diciembre de 2014, Rol No 883 2014, Id. MJ MJJ39680.

Corte de Apelaciones de Santiago, 5 de enero de 2015, Rol N 1403-2014, Id. MJ MJJ40061.

Corte de Apelaciones de Santiago, 6 de enero de 2015, Rol N 1464-2014, Id. Vlex 591278530.

Corte de Apelaciones de Santiago, 30 de enero de 2015, Rol No 1529-2014, Id. MJ MJJ40425.

Corte de Apelaciones de Santiago, 30 de enero de 2015, Rol N 1523-2014, Id. MJ MJJ40423.

Corte de Apelaciones de Valdivia, 2 de febrero de 2015, Rol N 179-2014, Id. LP CL/JUR/535/2015.

Corte de Apelaciones de Concepción, 8 de abril de 2015, Rol N 41-2014, Id. Vlex 577682150.

Corte de Apelaciones de Santiago, 24 de abril de 2015, Rol N 1078-2014, Id. LP CL/JUR/2282/2015.

Corte de Apelaciones de Santiago, 30 de abril de 2015, Rol N 108-2015, Id. LP CL/JUR/2399/2015. 
Corte de Apelaciones de Puerto Montt, 4 de mayo de 2015, Rol No 16-2015, Id. Vlex 569848690.

Corte de Apelaciones de Santiago, 13 de mayo de 2015, Rol N 92-2015, Id. Vlex 569854154.

Corte de Apelaciones de San Miguel, 18 de mayo de 2015, Rol No $761-$ 2015, Id. Vlex 571428686.

Corte de Apelaciones de Santiago, 13 de mayo de 2015, Rol N 92-2015, Id. Vlex 569854154.

Corte de Apelaciones de San Miguel, 18 de mayo de 2015, Rol № 760 2015, Id. Vlex 571428682.

Corte de Apelaciones de San Miguel, 2 de junio de 2015, Rol ํo 758-2015, Id. MJ MJJ41918.

Corte de Apelaciones de Santiago, 30 de junio de 2015, Rol No 409-2015, Id. MJ MJJ41951.

Corte Suprema, 30 de junio de 2015, Rol № 5840-2015, Id. Vlex 576395738.

Corte de Apelaciones de Valdivia, 10 de julio de 2015, Rol N ${ }^{\circ} 102-2015$, Id. Vlex 577716202.

Corte de Apelaciones de Concepción, 20 de julio de 2015, Rol No 458 2014, Id. Vlex 631916801.

Corte de Apelaciones de Valdivia, 31 de julio de 2015, Rol N 132-2015, Id. LP CL/JUR/4396/2015.

Corte de Apelaciones de Concepción, 7 de agosto de 2015, Rol № 4942015, Id. Vlex 579880238.

Corte de Apelaciones de Santiago, 7 de agosto de 2015, Rol N ${ }^{\circ} 748-2015$, Id. Vlex 579880230.

Corte de Apelaciones de Iquique, 21 de agosto de 2015, Rol N 48-2015, Id. LP CL/JUR/4766/2015.

Corte de Apelaciones de Talca, 21 de agosto de 2015, Rol № 24-2015, Id. LP CL/JUR/4770/2015.

Corte de Apelaciones de Valdivia, 21 de agosto de 2015, Rol N 135-2015, Id. LP CL/JUR/4772/2015.

Corte de Apelaciones de Santiago, 31 de agosto de 2015, Rol № 822-2015, Id. LP CL/JUR/4968/2015.

Corte de Apelaciones de Santiago, 3 de diciembre de 2015, Rol 1359-2015, Id. Vlex 644248793.

Corte de Apelaciones de Santiago, 11 de diciembre de 2015, Rol No 1077 2015, Id. LP CL/JUR/7746/2015.

Corte de Apelaciones de Santiago, 14 de diciembre de 2015, Rol No 1220 2015, Id. MJ MJJ43192.

Corte de Apelaciones de Santiago, 24 de diciembre de 2015, Rol N 1361 - 
2015, Id. LP CL/JUR/8065/2015.

Corte de Apelaciones de Rancagua, 1 de abril de 2016, Rol N 136-2015, Id. LP CL/JUR/2357/2016.

Corte de Apelaciones de Santiago, 15 de junio de 2016, Rol N 405-2016, Id. Vlex 646944973.

CL/JUR/8065/2015.

Corte de Apelaciones de Santiago, 17 de junio de 2016, Rol N²77-2016, Id. Vlex 646975401.

Corte de Apelaciones de Santiago, 13 de julio de 2016, Rol N ${ }^{\circ}$ 545-2016, Id. Vlex 645601129.

Corte de Apelaciones de Santiago, 27 de julio de 2016, Rol No 476-2016, Id. Vlex 646927377.

Corte de Apelaciones de Valdivia, 27 de septiembre de 2016, Rol 257-2016, Id. Vlex 674594373.

Corte de Apelaciones de Santiago, 28 de septiembre de 2016, Rol N $1164-$ 2016, Id. MJ MJJ45893.

Corte de Apelaciones de Valdivia, 7 de octubre de 2016, Rol N² 260-2016, Id. Vlex 655099985.

Corte de Apelaciones de Santiago, 3 de noviembre de 2016, Rol N $1294-$ 2016, Id. LP 653216493.

Corte de Apelaciones de Concepción, 1 de diciembre de 2016, Rol 3962016, Id. Vlex 654595209.

Corte de Apelaciones de Santiago, 14 de diciembre de 2016, Rol N ${ }^{\circ} 287-$ 2016, Id. LP CL/JUR/8341/2016.

Corte de Apelaciones de Santiago, 14 de diciembre de 2016, Rol N ${ }^{\circ} 1047$ 2015, Id. LP CL/JUR/9340/2016.

Corte Suprema, 23 de enero de 2017, Rol № 68769-2016, Id. LP CL/ JUR/230/2017.

Corte Suprema, 23 de enero de 2017, Rol N 68771-2016, Id. LP CL/ JUR/229/2017.

Corte de Apelaciones de Concepción, 27 de marzo 2017, Rol № 64-2017, Id. Vlex 672259117.

\section{BASES DE DATOS UTILIZADAS}

Base de datos de Jurisprudencia Vlex, www.vlex.cl

Base de datos de Jurisprudencia Legal Publishing, www.legalpublishing.cl

Base de datos de Jurisprudencia Micro juris, www.microjuris.cl 